\title{
Glacial Variability Over the Last Two Million Years: An Extended Depth-Derived Agemodel, Continuous Obliquity Pacing, and the Pleistocene Progression
}

\section{Citation}

Huybers, Peter. 2007. Glacial variability over the last two million years: An extended depthderived agemodel, continuous obliquity pacing, and the Pleistocene progression. Quaternary Science Reviews 26(1-2): 37-55.

\section{Published Version}

http://dx.doi.org/10.1016/j.quascirev.2006.07.013

\section{Permanent link}

http://nrs.harvard.edu/urn-3:HUL.InstRepos:3207710

\section{Terms of Use}

This article was downloaded from Harvard University's DASH repository, and is made available under the terms and conditions applicable to Other Posted Material, as set forth at http:// nrs.harvard.edu/urn-3:HUL.InstRepos:dash.current.terms-of-use\#LAA

\section{Share Your Story}

The Harvard community has made this article openly available.

Please share how this access benefits you. Submit a story.

\section{Accessibility}




\title{
Glacial variability over the last two million years: an extended depth-derived agemodel, continuous obliquity pacing, and the Pleistocene progression
}

\author{
Peter Huybers* \\ Department of Geology and Geophysics, Woods Hole Oceanographic Institution, Woods Hole, MA, 02540, USA
}

Received 11 November 2005; received in revised form 21 May 2006; accepted 21 July 2006

\begin{abstract}
An agemodel not relying upon orbital assumptions is estimated over the last $2 \mathrm{Ma}$ using depth in marine sediment cores as a proxy for time. Agemodel uncertainty averages $\pm 10 \mathrm{Ka}$ in the early Pleistocene $(\sim 2-1 \mathrm{Ma})$ and $\pm 7 \mathrm{Ka}$ in the late Pleistocene $(\sim 1 \mathrm{Ma}$ to the present). Twelve benthic and five planktic $\delta^{18} \mathrm{O}$ records are pinned to the agemodel and averaged together to provide a record of glacial variability. Major deglaciation features are identified over the last $2 \mathrm{Ma}$ and a remarkable 33 out of 36 occur when Earth's obliquity is anomalously large. During the early Pleistocene deglaciations occur nearly every obliquity cycle giving a $40 \mathrm{Ka}$ timescale, while late Pleistocene deglaciations more often skip one or two obliquity beats, corresponding to 80 or $120 \mathrm{Ka}$ glacial cycles which, on average, give the $\sim 100 \mathrm{Ka}$ variability. This continuous obliquity pacing indicates that the glacial theory can be simplified. An explanation for the $\sim 100 \mathrm{Ka}$ glacial cycles only requires a change in the likelihood of skipping an obliquity cycle, rather than new sources of long-period variability. Furthermore, changes in glacial variability are not marked by any single transition so much as they exhibit a steady progression over the entire Pleistocene. The mean, variance, skewness, and timescale associated with the glacial cycles all exhibit an approximately linear trend over the last $2 \mathrm{Ma}$. A simple model having an obliquity modulated threshold and only three adjustable parameters is shown to reproduce the trends, timing, and spectral evolution associated with the Pleistocene glacial variability.
\end{abstract}

(C) 2006 Elsevier Ltd. All rights reserved.

Keywords: Glacial cycles; Mid-Pleistocene transition; Geochronology; Obliquity; Orbital forcing; Hypothesis test

\section{Introduction}

The onset of glaciation near $3 \mathrm{Ma}$ is thought to owe to a gradual cooling trend over the last $4 \mathrm{Ma}$ (Shackleton and Hall, 1984; Raymo, 1994; Ravelo et al., 2004) which is itself part of a longer-term trend over the last $50 \mathrm{Ma}$ (Zachos et al., 2001). Early-Pleistocene ( 2-1 Ma) glacial cycles have a $40 \mathrm{Ka}$ timescale; thus these cycles are readily attributed to the $40 \mathrm{Ka}$ changes in Earth's obliquity (e.g. Raymo and Nisancioglu, 2003; Huybers, 2006). In

\footnotetext{
*Harvard University, Earth and Planetary Sciences, Museum Bldg. rm405, 20 Oxford St., Cambridge MA 02138, USA. Tel.: + 1617233 3295; fax: +15084572187 .

E-mail addresses: phuybers@whoi.edu, phuybers@fas.harvard.edu.
}

contrast, late-Pleistocene ( $\sim$ Ma-present) glacial cycles have a longer $\sim 100 \mathrm{Ka}$ timescale often attributed to orbital precession (Hays et al., 1976; Imbrie et al., 1992; Ghil, 1994).

Existing hypotheses for this "mid-Pleistocene transition" (or mid-Pleistocene revolution) from 40 to $\sim 100 \mathrm{Ka}$ glacial cycles call for shifts in the controls on glaciation to activate new sources of low-frequency variability (Saltzman and Sutera, 1987; Maasch and Saltzman, 1990; Ghil, 1994; Raymo, 1997; Paillard, 1998; Clark et al., 1999; Tziperman and Gildor, 2003; Ashkenazy and Tziperman, 2004). The recent results of Huybers and Wunsch (2005) (hereafter HW05), however, show that the late Pleistocene glacial terminations are paced by changes in Earth's obliquity, suggesting that a more unified glacial theory is possible, 
related to obliquity both during the early and late Pleistocene. Here, the argument is made that the progression from 40 to $\sim 100 \mathrm{Ka}$ glacial cycles is not marked by any specific transition and does not require any real change in the physics of glacial cycles.

The paper is organized as follows: In Section 2 the depthderived agemodel of Huybers and Wunsch (2004) (hereafter HW04) is extended from 0.8 to $2 \mathrm{Ma}$. The reader not interested in agemodel construction may safely skip this section. In Section 3 the hypothesis testing procedures outlined in HW05 (but now applied to many more observations) are used to evaluate the relationship between orbital variations and glacial variability. Section 4 discusses the trends in Pleistocene glacial variability, and Section 5 presents a simple model which describes these trends and the timing of the glacial cycles. The paper is concluded in Section 6.

\section{The timing of Pleistocene glaciation}

The use of age estimates not depending on orbital assumptions are required to avoid circular reasoning when assessing the link between glacial and orbital variability. This section presents an extension of the depth-derived agemodel of HW04 from 0.8 to $2.0 \mathrm{Ma}$. This agemodel improves on previous non-orbitally tuned Pleistocene age estimates (Williams et al., 1988; Raymo and Nisancioglu, 2003) by combining numerous age-depth relationships, correcting for down-core compaction, and by providing for age uncertainty estimates. Most agemodels spanning the Pleistocene (e.g. Shackleton et al., 1990; Lisiecki and Raymo, 2005) constrain ages by aligning variations in the $\delta^{18} \mathrm{O}$ record with variations in the orbital parameters, thus precluding an objective evaluation of the orbital influence on glacial timing.

\subsection{Converting depth to age}

Conversion of sediment core depths into age estimates is based on the graphic correlation methodology of Shaw (1964) and detailed in HW04. Only those instances where the methodology is extended or altered from HW04 are dwelled on here. Geomagnetic age control comes from the Brunhes-Matuyama transition (B-M) $(0.78 \mathrm{Ma})$, the Jaramillo (0.99-1.07 Ma), and Olduvai (1.77-1.95 Ma) subchrons, and the Matuyama-Gauss transition (2.58 Ma) (Berggren et al., 1995; Cande and Kent, 1995). These geomagnetic ages are derived from a combination of radiometric dating techniques, sea-floor spreading rates, and astronomically derived age estimates - the last indicating that geomagnetic age estimates do contain limited orbital assumptions. However, only six geomagnetic ages are utilized in the course of $2 \mathrm{Ma}$ and the orbital assumptions are but one constraint on the geomagnetic ages, minimizing the influence of the orbital assumptions. Also, the $\mathrm{B}-\mathrm{M}$ is radiometrically dated to sufficient accuracy $( \pm 2 \mathrm{Ka})$ (Singer and Pringle, 1996) that it is essentially independent of orbital assumptions, and thus so is the agemodel between the present and $0.78 \mathrm{Ma}$. Geomagnetic events are assumed to occur in the same isotopic stages identified by Raymo and Nisancioglu (2003) for core DSDP607.

References and statistics for each sediment core used in this study are given in Table 1. Approximately synchronous time horizons are identified between sediment cores by identifying corresponding $\delta^{18} \mathrm{O}$ events in the separate stratigraphies. (Event synchronization is limited by the signal propagation time through the ocean and the resolution of the $\delta^{18} \mathrm{O}$ stratigraphy.) HW04 identified 17 events over $780 \mathrm{Ka}$, giving an average event spacing of $46 \mathrm{Ka}$. Here, a total of $104 \delta^{18} \mathrm{O}$ events are identified between the present and the Matuyama-Gauss transition providing an average $\delta^{18} \mathrm{O}$ event spacing of $24 \mathrm{Ka}$ (see

Table 1

Sediment cores

\begin{tabular}{|c|c|c|c|c|c|c|}
\hline Name & Reference & Species & $\bar{S}$ & $\Delta t$ & Lat. & Lon. \\
\hline MD900963 & Bassinot et al. (1994) & $\mathrm{P}$ & 4.6 & 2.3 & $5 \mathrm{~N}$ & $74 \mathrm{E}$ \\
\hline ODP664 & Raymo (1997) & B & 3.7 & 3.4 & 0 & $23 \mathrm{~W}$ \\
\hline ODP677 & Shackleton et al. (1990) & $\mathrm{B}, \mathrm{P}$ & 3.9 & $2.1,1.8$ & $1 \mathrm{~N}$ & $84 \mathrm{~W}$ \\
\hline ODP846 & Mix et al. (1995a) & B & 3.7 & 2.5 & $3 \mathrm{~S}$ & $91 \mathrm{~W}$ \\
\hline ODP927 & Cullen and Curry (1997), and Curry and Cullen (1997) & $\mathrm{B}, \mathrm{P}$ & 4.5 & $3.2,2.2$ & $6 \mathrm{~N}$ & $43 \mathrm{~W}$ \\
\hline ODP980 & Flower (1999), McManus et al. (1999, 2002), and Oppo et al. $(1998,2001)$. & B & 12.3 & 1.6 & $55 \mathrm{~N}$ & $17 \mathrm{~W}$ \\
\hline ODP982 & Venz et al. (1999). & $\mathrm{B}, \mathrm{P}$ & 2.5 & $2.3,2.0$ & $57 \mathrm{~N}$ & $18 \mathrm{~W}$ \\
\hline ODP983 & Channell et al. (1997) and McManus et al. (2003) & B & 11.4 & 0.9 & $61 \mathrm{~N}$ & $22 \mathrm{~W}$ \\
\hline TT013-PC18 & Murray et al. (2000) & $\mathrm{B}$ & 1.5 & 3.7 & $2 \mathrm{~S}$ & $140 \mathrm{~W}$ \\
\hline TT013-PC72 & Murray et al. (2000) & $\mathrm{B}$ & 1.6 & 3.3 & 0 & $139 \mathrm{~W}$ \\
\hline
\end{tabular}

Characteristics and primary references for each core. Columns from left to right display $\delta^{18} \mathrm{O}$ species benthic (B) and/or planktic (P), the mean sediment accumulation rate $(\bar{S}, \mathrm{~cm} / \mathrm{Ka})$, the mean interval between $\delta^{18} \mathrm{O}$ measurements $(\triangle t, \mathrm{Ka})$, and the latitude and longitude of each core site. 


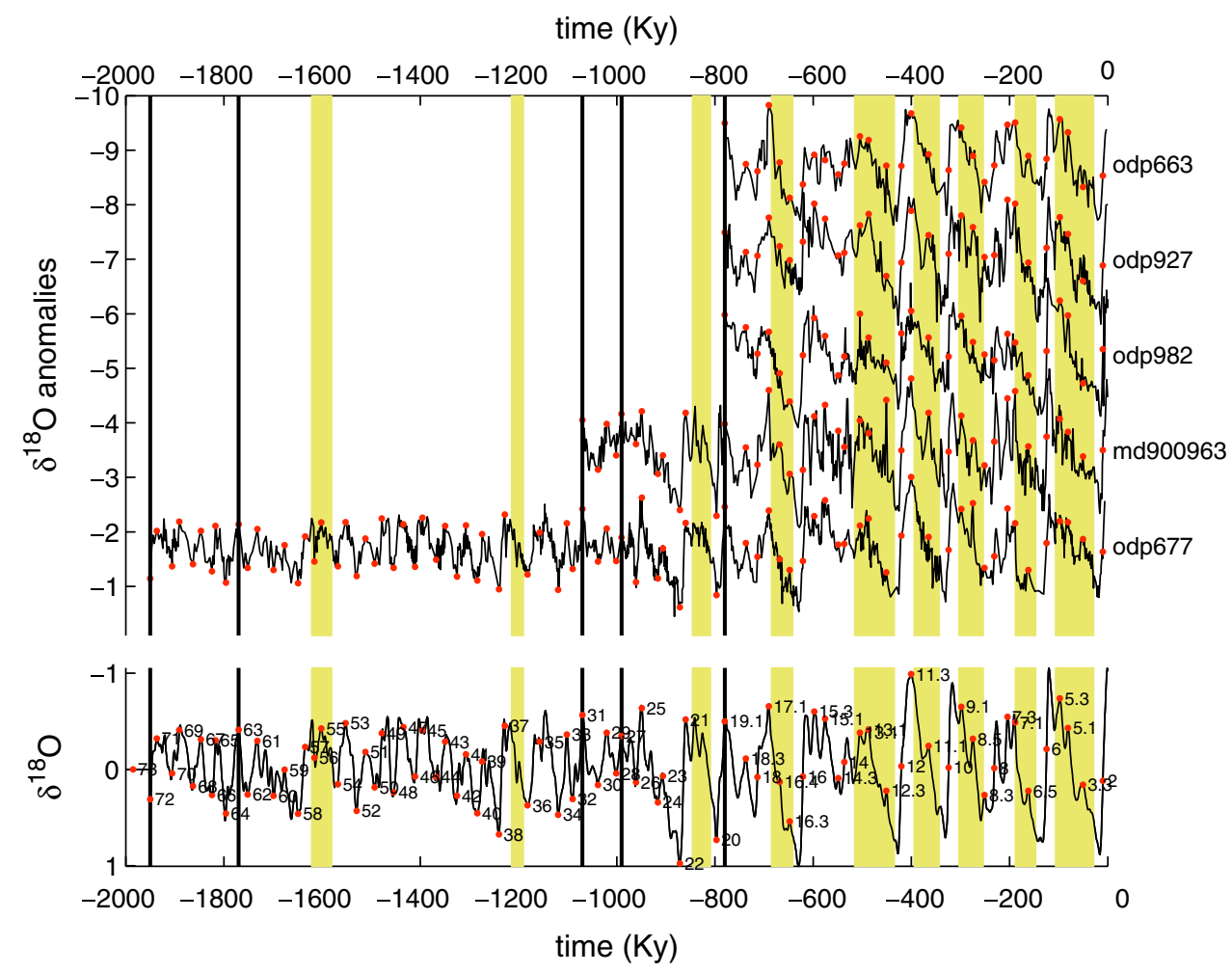

Fig. 1. Planktic $\delta^{18} \mathrm{O}$ records pinned to the extended depth-derived agemodel. Note that time runs from left to right. Shown are anomalies with respect to $0.7-0 \mathrm{Ma}$, records are offset from one another by $1.75 \%$. Vertical lines indicate geomagnetic events used for age control (not showing the Matuyama-Gauss reversal at $2.58 \mathrm{Ma}$ ). Dots indicate events pinned to the depth-derived agemodel. Vertical shading indicates where more than one obliquity cycle elapses between deglacial events. At bottom is the averaged planktic stack with age-control points labeled according to the isotopic stage notation of Ruddiman et al. (1989).

Figs. 1 and 2). Event identification follows the $\delta^{18} \mathrm{O}$ stage notation of Ruddiman et al. (1989), Raymo et al. (1989), and Shackleton (1995). Increasing the number of agecontrol points decreases agemodel uncertainty and better preserves the structure of the $\delta^{18} \mathrm{O}$ variability when records are averaged (Huybers, 2004).

In order to accurately identify $\delta^{18} \mathrm{O}$ features at a resolution of $24 \mathrm{Ka}$, a relatively high $\delta^{18} \mathrm{O}$ sampling rate is required. Only those records having a sampling resolution of four $\mathrm{Ka}$ or less are included in this study, reducing the total number of records from 21 in HW04 to 14 here. This leads to small changes in the depth-derived ages of $\pm 4 \mathrm{Ka}$, consistent with the estimated uncertainties. Details of this agemodel and differences with respect to that of HW04 are given in the supplementary material.

Ages are assigned to each $\delta^{18} \mathrm{O}$ event by interpolating age with depth between the geomagnetic events. This provides as many estimates of the age of each $\delta^{18} \mathrm{O}$ event as there are sediment cores. The averages of the event ages are expected to be more accurate than any single event age and serve as a master chronology. A complete agemodel is estimated for each sediment core by linearly interpolating age with depth between each of the average event ages. Note that following the methodology of HW04, depth in each sediment core has been corrected for the effects of compaction.
There are 14 sediment cores which extend to the B-M transition, nine to the bottom of the Jaramillo, four to the bottom of the Olduvai, and two extend back to the Matuyama-Gauss transition. The choice is made to truncate cores at the oldest geomagnetic event which they reach. This prevents having to extrapolate age-depth relationships outside of regions bounded by geomagnetic or core-top age control. Such a truncation is chosen because age error is expected to grow six times more quickly when one end of the age-depth relationship is not constrained in time (HW04).

\subsection{Agemodel uncertainty}

A Monte Carlo approach is used to estimate agemodel uncertainty. Uncertainty estimates account for sediment accumulation rate variations, sediment compaction, the time for the $\delta^{18} \mathrm{O}$ signal to propagate throughout the oceans, and uncertainty in magnetic event ages and their identification relative to $\delta^{18} \mathrm{O}$ stages. Unless otherwise stated, uncertainty estimates follow HW04.

It is assumed that there are as many degrees of freedom as there are sediment cores. This differs from HW04 where the degrees of freedom were assumed to be fewer than the total number of cores owing to covariation between accumulation rates at different cites. Further analysis, 


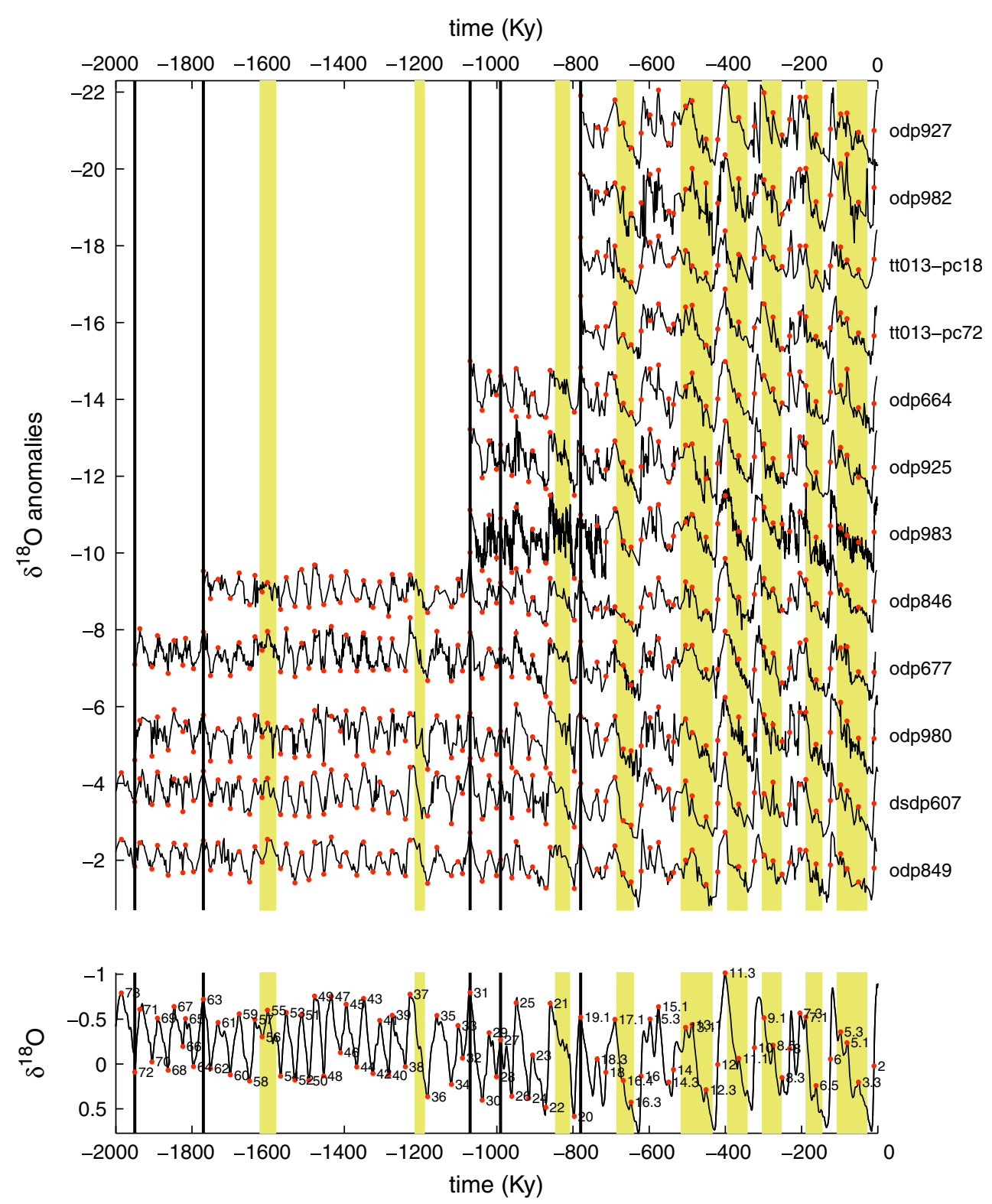

Fig. 2. Similar to Fig. 3 but for benthic $\delta^{18} \mathrm{O}$ records.

based on the cores used in this study, indicates that accumulation rate variations are as likely to be anticorrelated as they are to be positively correlated so that there appears no reason to reduce the total number of degrees of freedom. This assumption of greater degrees of freedom along with a greater number of $\delta^{18} \mathrm{O}$ events reduces average uncertainty estimates from $\pm 9 \mathrm{Ka}$ in HW04 to $\pm 7 \mathrm{Ka}$ for the period between the B-M and the present.

The correction for sediment compaction, on average, makes ages $10 \mathrm{Ka}$ younger between the $\mathrm{B}-\mathrm{M}$ and the present. The influence of compaction on earlier ages is much smaller-on average making ages $1 \mathrm{Ka}$ youngerprimarily because changes in compaction are less pronounced further down-core (Bahr et al., 2001). A secondary reason is that geomagnetic events, which fix event ages independent of compaction, are more closely spaced between the B-M and Matuyama-Gauss transitions than between the $\mathrm{B}-\mathrm{M}$ and present. The average magnitude of the compaction correction uncertainty below the B-M is taken to be $\pm 0.5 \mathrm{ka}$.

Geomagnetic ages are assumed to be known to within $\pm 5 \mathrm{Ka}$ (Berggren et al., 1995; Cande and Kent, 1995) except for the $\mathrm{B}-\mathrm{M}$ which is known to within $\pm 2 \mathrm{Ka}$. An additional $\pm 2 \mathrm{Ka}$ is added to account for uncertainty in the identification of when a geomagnetic event occurs within a sediment core (Tauxe et al., 1996).

The estimated agemodel uncertainty is shown in Fig. 3. Uncertainty tends to grow away from geomagnetic and $\delta^{18} \mathrm{O}$ events and follows a Brownian bridge structure (see HW04). Agemodel uncertainty averages $\pm 10 \mathrm{Ka}$ during the early Pleistocene and $\pm 7 \mathrm{Ka}$ during the late Pleistocene. Late-Pleistocene ages are more certain because of the greater number of sediment cores. 


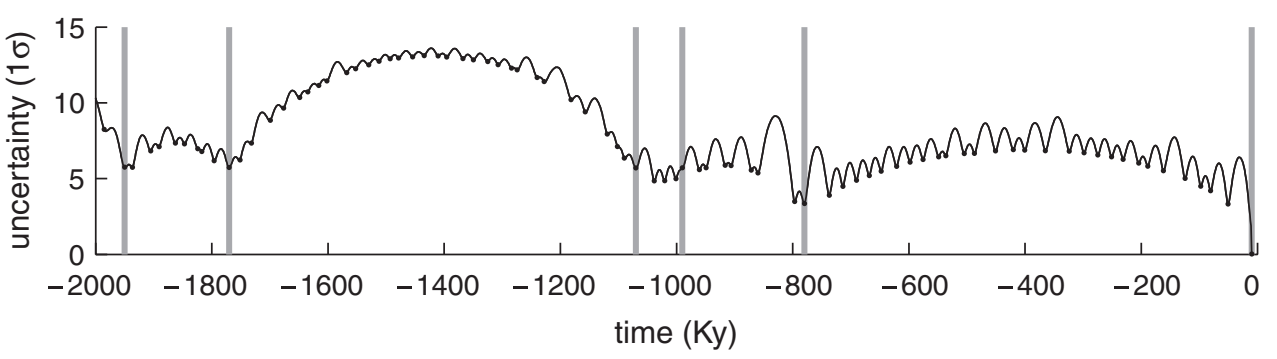

Fig. 3. Estimated agemodel uncertainty. Shown is the one standard deviation of $10^{4}$ Monte Carlo agemodel realizations. Dots indicate the isotopic events used to align the records and vertical bars indicate geomagnetic age constraints, excepting the youngest bar which is the radiometrically dated termination one feature.

Although not relying on orbital assumptions itself, the extended depth-derived agemodel is similar to orbitally tuned estimates. The difference between the extended depth-derived ages and the orbitally tuned agemodel of Lisiecki and Raymo (2005) has a standard deviation $(\sigma)$ of only $\pm 6 \mathrm{Ka}$, less than the expected uncertainty for the depth-derived ages. The small standard deviation could owe to the fact that the Lisiecki and Raymo (2005) agemodel estimation procedure explicitly seeks to minimize variations in accumulation rate, an approach not unlike the depth-derived procedure. Differences between the extended depth-derived agemodel and the agemodel of Shackleton (1995) have $\sigma= \pm 7 \mathrm{Ka}$. Interestingly, the two orbitally tuned agemodels (Shackleton, 1995; Lisiecki and Raymo, 2005) have discrepancies over the last $2 \mathrm{Ma}$ of $\sigma= \pm 6 \mathrm{Ka}$, similar to the discrepancies between the depth-derived and orbitally tuned age estimates. It can be inferred that the orbitally tuned age estimates are unlikely to be more accurate than the depthderived ages.

\subsection{Averaged $\delta^{18} \mathrm{O}$ record}

To reduce noise owing to measurement error and local climate variability (e.g. Mix, 1987), the individual $\delta^{18} \mathrm{O}$ records are averaged using the extended depth-derived agemodel. Prior to averaging, however, it is necessary to account for mean offsets between the $\delta^{18} \mathrm{O}$ records, owing primarily to mean differences in water temperature but also to differences in the ambient $\delta^{18} \mathrm{O}$ of the water and vital effects (e.g. Lynch-Stieglitz et al., 1999). Otherwise, when short records drop out back in time the mean value would change. To account for these mean offsets in $\delta^{18} \mathrm{O}$, the record average between $0.7 \mathrm{Ma}$ and the present is subtracted from each record.

Averaging requires that all records first be interpolated to the same sample spacing. To account for differing sampling resolution between cores, records are weighted according to the inverse of the average sampling resolution,

$$
\begin{aligned}
\bar{y}(t)= & \sum_{i=1}^{N(t)} w(t, i) \times y^{\prime}(t, i), \\
& w(t, i)=u(t) \times s(i)^{-1} .
\end{aligned}
$$

Here, $\bar{y}(t)$ is the average $\delta^{18} \mathrm{O}$ at time $t, N(t)$ is the number of records available as, function of time, and $y^{\prime}(t, i)$ is the $\delta^{18} \mathrm{O}$ anomaly of the $i$ th record relative to the average between $0.7 \mathrm{Ma}$ and the present. The average sampling resolution is given by $s(i)$ and $u$ is a constant chosen so that the sum of the weights always equals unity, $\sum_{i=1}^{N(t)} w(t, i)=1$. Eq. (2) ensures that the contribution of each record to the average is proportional to the number of data points it contributes. Prior to averaging, records are smoothed using a running $5 \mathrm{Ka}$ average to help suppress noise and local climate variability.

Fig. 4 shows the averaged $\delta^{18} \mathrm{O}$ record, referred to as the stack, plotted against the $\delta^{18} \mathrm{O}$ compilation of Lisiecki and Raymo (2005). The two records have very similar structures. When the Lisiecki and Raymo (2005) compilation is placed on the depth-derived agemodel (see the supplementary material) the cross correlation with the depth-derived stack is 0.95 .

An evolutionary spectrum of the depth-derived stack shows the usual features: variability is primarily concentrated at $40 \mathrm{Ka}$ periods during the early Pleistocene and at $\sim 100 \mathrm{Ka}$ periods during the late Pleistocene. The onset of $100 \mathrm{Ka}$ variability is concomitant with increased variability near $\sim 20 \mathrm{Ka}$. Prior to drawing any conclusion from the evolutionary spectrum, however, it is useful to analyze the stack using a few other statistical methods.

\section{A test of the orbital hypothesis}

HW05 showed that the timing of glacial terminations during the late Pleistocene coincide with periods of increased obliquity. Here, those results are extended to include both early-Pleistocene deglacial events and smaller amplitude deglacial events during the late Pleistocene. The increased number of observations increases the statistical power of the test. Furthermore, the longer record places the late-Pleistocene glacial termination in the perspective of the earlier, smaller amplitude, and shorter period variations.

A formal hypothesis test is conducted. The hypothesis, $\mathrm{H}_{1}$, is that deglaciations are triggered at a particular phase of Earth's obliquity. The null hypothesis, $\mathrm{H}_{0}$, is that deglaciations are independent of the phase of obliquity. Discussion is framed around obliquity because 

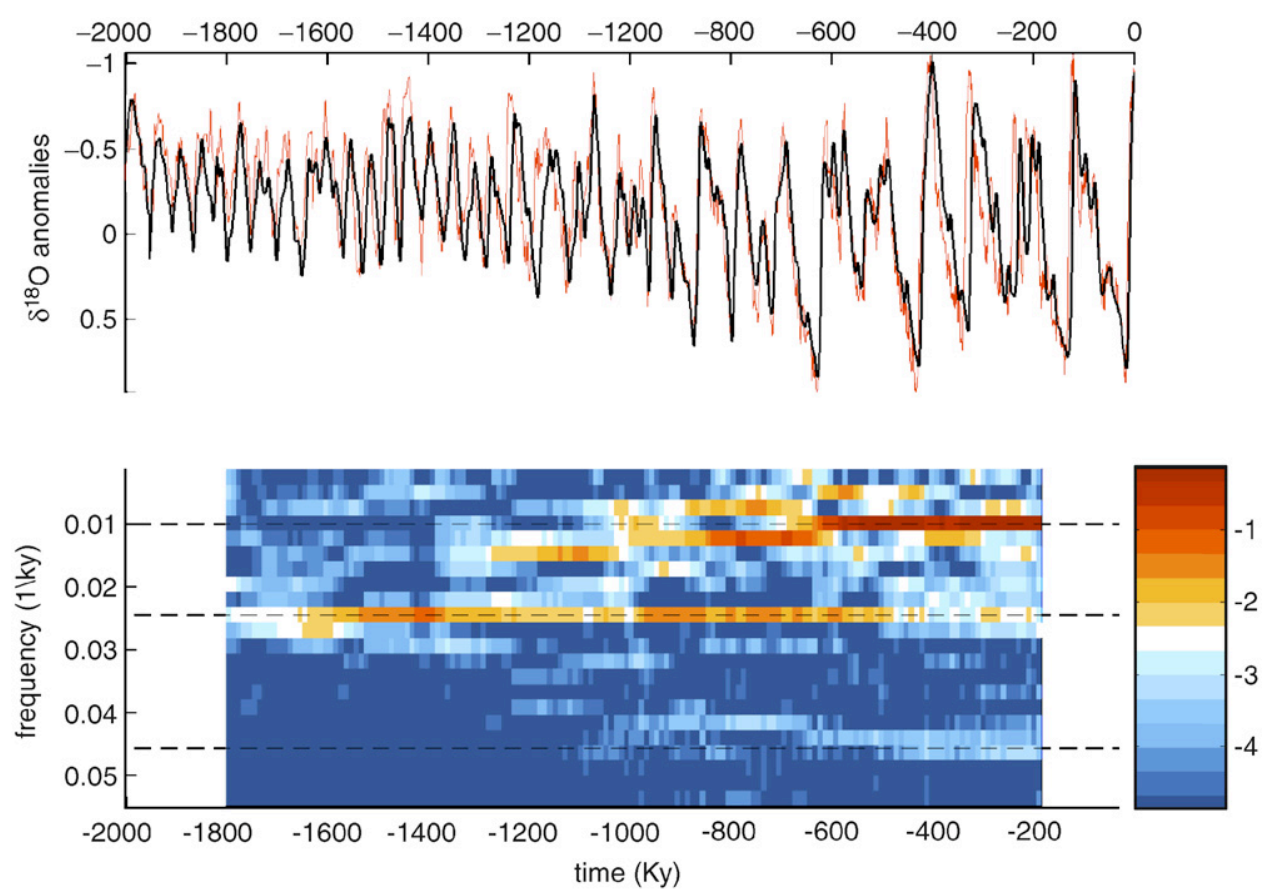

Fig. 4. Glacial variability over the last $2 \mathrm{Ma}$. The averaged $\delta^{18} \mathrm{O}$ record is shown at top on the depth-derived agemodel (thick line). For comparison, the $\delta^{18} \mathrm{O}$ compilation of Lisiecki and Raymo (2005) is also shown (thin line). Units are in \%o and the mean between $700 \mathrm{Ka}$ and the present has been removed. An evolutionary spectrum of the depth-derived record is shown at bottom. Shading indicates the $\log _{10}$ of the spectral power. Spectra are calculated using a $400 \mathrm{Ka}$ sliding window. Horizontal dashed lines are at 1/100, 1/41, and 1/22 Ka.

the early-Pleistocene variability is characterized by $40 \mathrm{Ka}$ periods (Raymo and Nisancioglu, 2003) and the latePleistocene glacial terminations are known to initiate during times of increased obliquity (HW05). Precession and eccentricity are also considered. The orbital pacing of the early $(\sim 2-1 \mathrm{Ma})$ and late-Pleistocene (1 Ma to the present) glacial variability are tested separately as these are generally characterized as distinct modes of glacial variability.

To conduct the hypothesis test three elements are required: (1) an objective identification of what constitutes a deglacial event and when it occurs, (2) a test statistic to measure the stability of deglacial timing with respect to orbital variations, and (3) an estimate of the probability distribution functions (PDFs) associated with $\mathrm{H}_{0}$ and $\mathrm{H}_{1}$. Each element is discussed in turn.

\subsection{Identification}

The criterion adopted for identification of deglacial events is that the increase in $\delta^{18} \mathrm{O}$ (decrease in ice volume) between a local minimum and the following maximum must exceed one standard deviation of the $\delta^{18} \mathrm{O}$ record, i.e. greater than $0.35 \%$. To ensure only sustained events are identified, the stack is first smoothed using a $5 \mathrm{Ka}$ running average. A total of 36 events are identified, 20 in the early Pleistocene and 16 in the late. This large number of events, relative to the seven glacial terminations considered in HW05, permits more accurate differentiation between $\mathrm{H}_{0}$ and $\mathrm{H}_{1}$. If a different magnitude is used as the criterion for identification of events, for example one-half or two standard deviations of the stack, the number of identified events changes, but the results of the hypothesis test are unaffected.

Two options for defining a unique time for each deglacial event are the half-way-point in time or the half-way-point in $\delta^{18} \mathrm{O}$ between the local minimum and maximum bracketing each deglaciation. Here the half-way-point in time is used because this is independent of the particular shape of the deglacial event. Test results are insensitive to which definition is used. Fig. 5 shows each deglaciation event.

\subsection{Rayleigh's $R$}

To measure the relationship between the timing of deglacial events and orbital variations it is useful to employ Rayleigh's $R$ (see Upton and Fingleton, 1989; HW05). First, the phase of obliquity is sampled at the mid-point of each deglacial event. Rayleigh's $R$ is then calculated by converting phases into unit vectors and computing the vector average,

$R=\frac{1}{N}\left|\sum_{n=1}^{N} \cos \phi_{n}+\mathrm{i} \sin \phi_{n}\right|$.

Here, $\phi_{n}$ is the phase of obliquity sampled at the $n$th deglacial event, and the vertical bars indicate the magnitude. $R$ is real and non-negative with a maximum value of one when the phases are all the same. 


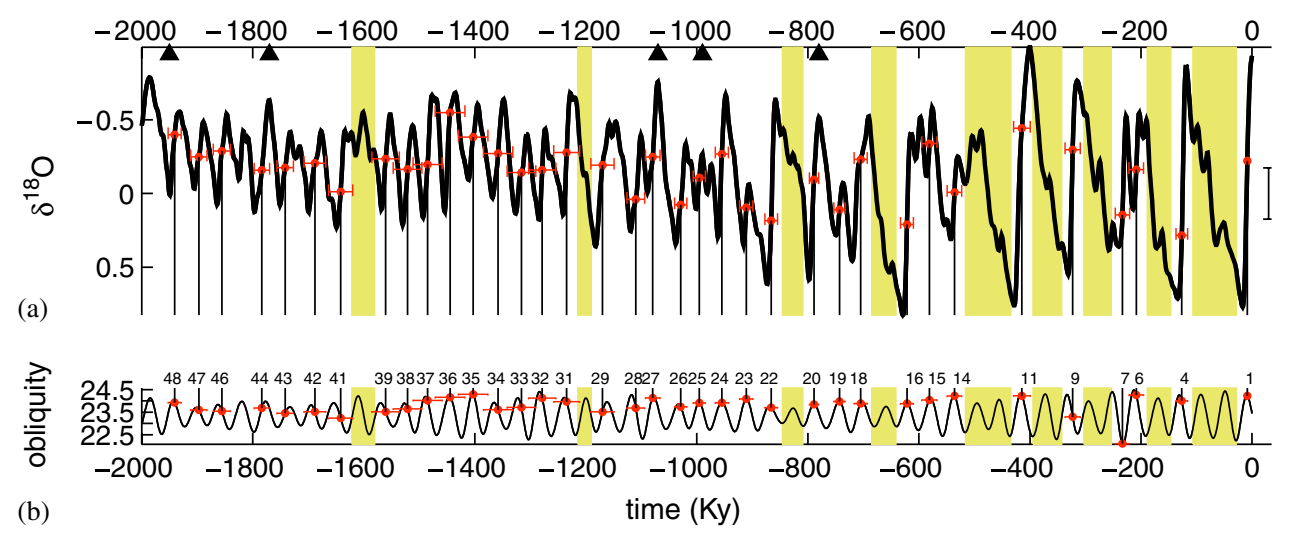

(c)
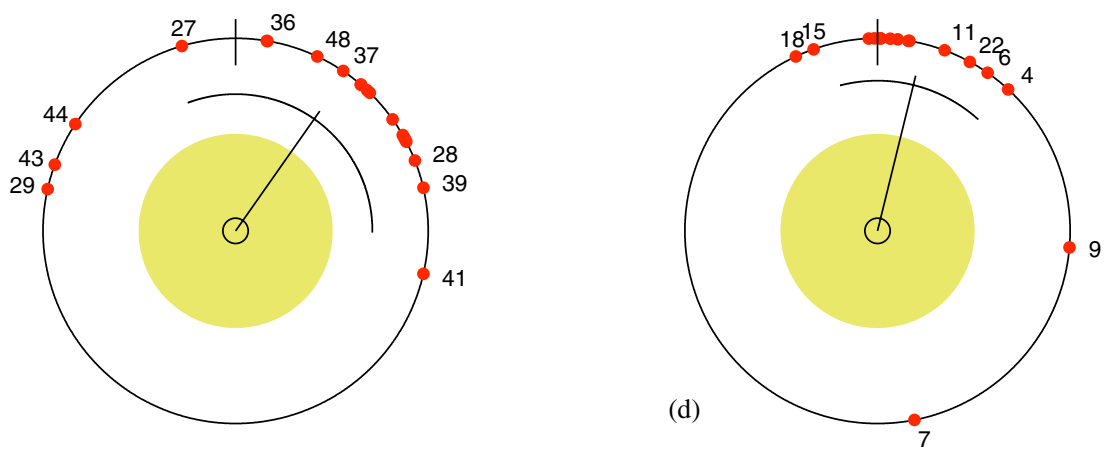

Fig. 5. Obliquity pacing over the last $2 \mathrm{Ma}$. (a) $\delta^{18} \mathrm{O}$ stack on the extended depth-derived agemodel. The magnitude of one standard deviation in $\delta^{18} \mathrm{O}$ is indicated at right, and deglacial events exceeding this magnitude are indicated by a dot. Horizontal bars indicate the two-standard-deviation agemodel uncertainty. Intervals where two or more obliquity cycles elapse between deglacial events are shaded. (b) The time variability of Earth's obliquity in degrees with the mid-point of each deglacial event indicated by a dot. (c,d) Unit circle with obliquity phases during each deglacial event plotted for the early (c) and late (d) Pleistocene. The vector average associated with each group of phases (Rayleigh's $R$ value) exceeds the $99 \%$ confidence level indicated by the shaded circle. The one-standard-deviation uncertainty in mean phase is indicated by the arc. Numbers above the obliquity record and plotted on the Rayleigh circles count the number of obliquity cycles starting from the present.

Compared with the more conventional use of Fourier analysis, Rayleigh's $R$ is well-suited for measuring the relationship between orbital and glacial variability. First, nonlinearities associated with the variable duration and asymmetry of the glacial cycles do not affect the statistic. Such nonlinearities complicate the Fourier representation, creating overtones and redistributing spectral energy throughout the continuum. Second, agemodel errors cause linear changes in the phase whereas even small agemodel errors can cause large and complicated distortions of the Fourier spectrum (see Thomson and Robinson, 1996). Finally, compared with most measures of phase-coupling, Rayleigh's $R$ requires fewer realizations in order to establish significance (Upton and Fingleton, 1989).

\subsection{Probability distributions for $\mathrm{H}_{0}$ and $\mathrm{H}_{1}$}

To obtain a PDF for $\mathrm{H}_{0}$ (that deglaciations are independent of orbital phasing) it is assumed that the orbital phase is uniformly distributed over 0 to $360^{\circ}$ with respect to the timing of deglaciations. A realization of $R$ for the early Pleistocene is obtained by sampling 20 phases from the uniform distribution. By binning $10^{4}$ such realization an estimate of the PDF is obtained. Similarly, an estimate of the PDF for the late Pleistocene is obtained by binning $R$ values computed using 16 random phases. If more complicated distributions are assumed for the phasing of the orbital variations, such as those derived from using surrogate data (Schreiber and Schmitz, 2000) or ensemble runs of a model (HW05), the hypothesis test results are unchanged.

The larger number of deglacial events permits more stringent testing of the orbital hypothesis. As opposed to the $5 \%$ significance level used in HW05, a $1 \%$ significance level is used here (i.e. $99 \%$ confidence that $\mathrm{H}_{0}$ can be rejected). The critical value at which $\mathrm{H}_{0}$ can be rejected for obliquity at the $1 \%$ level is $R=0.47$ for the early Pleistocene (having 20 events) and $R=0.52$ for the late Pleistocene (slightly larger because it has only 16 events). As a rule, test statistics will only be reported to one significant figure except when additional figures serve to make a point.

The probability distribution for $\mathrm{H}_{1}$, that deglacial events always occur during the same phase of obliquity, is somewhat more involved to estimate. A Monte Carlo technique is used (Press et al., 1999) where each deglacial event is assumed to initiate at a local maximum (zero phase) of obliquity. However, deglaciations will generally not be observed to occur at maximum obliquity owing to agemodel errors. To simulate this effect deglacial ages are 

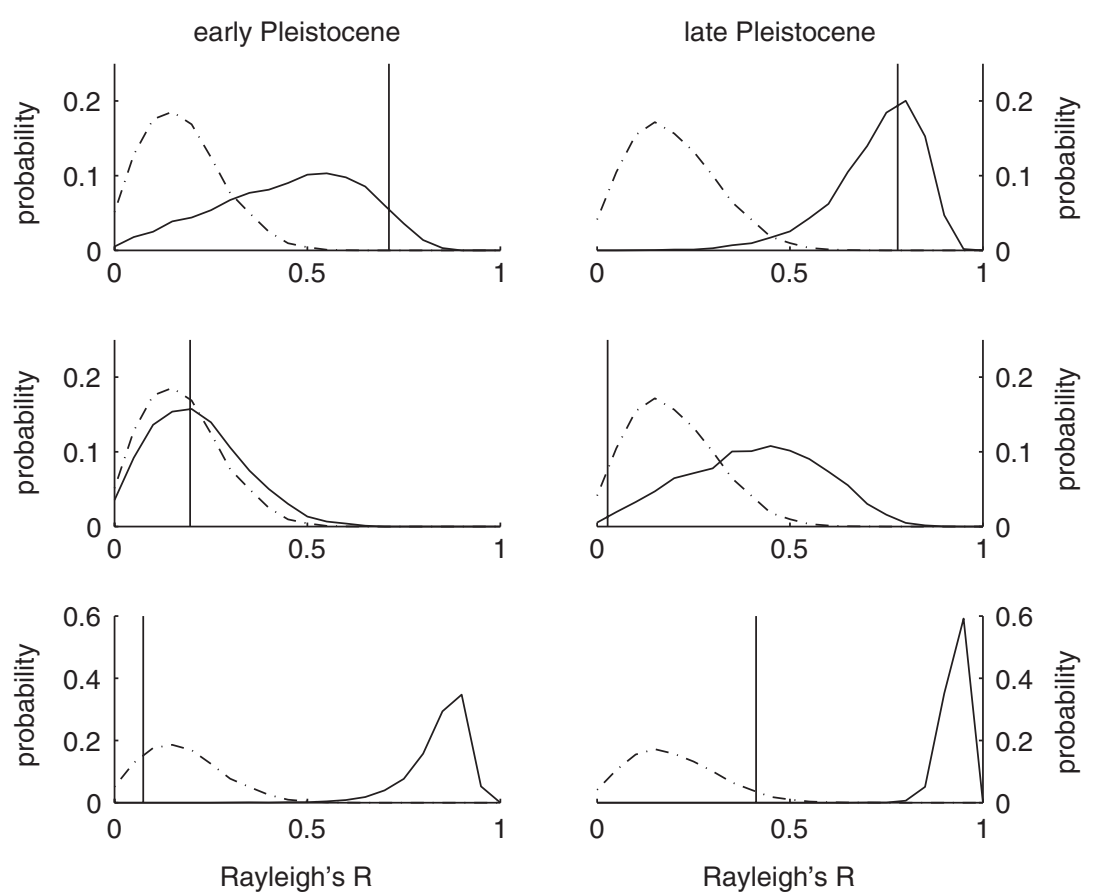

Fig. 6. Hypothesis test results. The left column is for the early Pleistocene (2-1 Ma) and the right column is for the late Pleistocene (1 Ma to the present). The top row is for obliquity, middle for precession, and bottom for eccentricity. Dashed lines indicated the probability distribution for $\mathrm{H}_{0}$, that deglaciations are independent of the orbital phase, while the solid lines are the probability distribution for $\mathrm{H}_{1}$, that deglaciations occur at maxima of an orbital parameter but are sampled subject to agemodel uncertainty. The Rayleigh's $R$ values calculated from the data are indicated by the vertical lines. $\mathrm{H}_{0}$ is rejected only for obliquity. Furthermore, the obliquity results are consistent with $\mathrm{H}_{1}$.

Table 2

Summary of hypothesis test results

\begin{tabular}{|c|c|c|c|c|c|c|c|c|}
\hline & \multicolumn{4}{|c|}{ Early Pleistocene (2-1 Ma) } & \multicolumn{4}{|c|}{ Late Pleistocene (1-0 Ma) } \\
\hline Precession & 0.2 & 0.5 & 0.0 & $\pm 88^{\circ}$ & 0.0 & 0.5 & 0.3 & $\pm 56^{\circ}$ \\
\hline Eccentricity & 0.1 & 0.5 & 1.0 & $\pm 24^{\circ}$ & 0.4 & 0.5 & 1.0 & $\pm 12^{\circ}$ \\
\hline
\end{tabular}

Columns from left to right are the observed Rayleigh's $R$ value, the critical value at which the null-hypothesis can be rejected at the $1 \%$ level, the power of the test, and the one-standard-deviation uncertainty associated with the mean phase. Columns are repeated for the early and late Pleistocene. Only the obliquity $R$ values permit rejection of the null hypothesis. Early-Pleistocene tests have a lower power and greater phase uncertainty owing to greater agemodel uncertainty.

perturbed according to the uncertainties estimated for the stack (see Section 2). The obliquity phase is then sampled at the perturbed ages and used to calculate realizations of $R$ for the early and late Pleistocene. By binning $10^{4}$ realizations of $R$, the probability distribution associated with $\mathrm{H}_{1}$ is estimated. The estimated distributions for $\mathrm{H}_{0}$ and $\mathrm{H}_{1}$ are shown in Fig. 6. Table 2 lists the critical values at which $\mathrm{H}_{0}$ can be rejected for each orbital parameter.

The uncertainty associated with the mean obliquity phase during deglaciations is also estimated using Monte Carlo techniques. The mean phase is calculated for each of the $10^{4}$ realizations discussed above, and the standard deviation of these mean phases gives the expected uncertainty. Note that much of the agemodel uncertainty is systematic - associated with magnetic reversal ages and auto-correlation in accumulation rates - thereby increasing uncertainty in the mean phase. Table 2 lists the mean phase uncertainty for each orbital parameter.

For the hypothesis test to be meaningful, the data must be capable of distinguishing between $\mathrm{H}_{0}$ and $\mathrm{H}_{1}$. The relevant quantity is known as the power of the test (e.g. Devore, 2000) and is the probability of correctly rejecting $\mathrm{H}_{0}$ when $\mathrm{H}_{1}$ is true. A low power indicates that even if deglaciations always occur at the same phase of obliquity the test is unlikely to discern this relationship. Table 2 lists the power of the test for each orbital parameter. The obliquity test during the late Pleistocene and eccentricity test during both the early and late Pleistocene are definitive, having powers of nearly 1. 
The larger agemodel uncertainty during the early Pleistocene decreases the associated obliquity power to 0.6 , but which is still large enough to permit a meaningful test. The power of the precession tests is small because agemodel uncertainty approaches half a precession cycle, and it is impossible to determine whether precession paces deglaciations.

\subsection{Test results}

During the early Pleistocene, the stability of the obliquity phase is significant at the $99 \%$ level $(R=0.7)$, as expected, given that early Pleistocene glacial cycles are known to have a $40 \mathrm{Ka}$ timescale (Pisias and Moore, 1981; Raymo et al., 1989; Ruddiman et al., 1989). More interestingly, late Pleistocene deglacial events have $R=0.8$. Thus, the late Pleistocene $100 \mathrm{Ka}$ world shows greater obliquity phase stability than the $40 \mathrm{Ka}$ world. In a sense, we are still in the $40 \mathrm{Ka}$ world. The Pleistocene obliquity phase stability is remarkable, with 33 of the 36 deglacial events occurring within $\pm 90^{\circ}$ of maximum obliquity. Apparently, the timing of deglacial events throughout the Pleistocene are controlled by obliquity variations. Mean phases are consistent with deglaciations initiating during maximum obliquity to within one standard deviation.

When the identical test is applied to precession and eccentricity, neither shows significant phase stability with respect to early or late Pleistocene deglaciations. Owing to the large power associated with the eccentricity test, it is clear that eccentricity does not pace the deglacial events. The precession test is inconclusive owing to the small power of the test.

The results of the test are insensitive to plausible reformulations. If a $5 \%$, rather than $1 \%$, significance level is adopted test results do not change. If deglacial events are identified using only the benthic or planktic records, test results are unaltered. Results are also unchanged if the Pleistocene record is divided into other intervals, as long as these span numerous obliquity cycles. It is thus concluded that obliquity paces both the early and late Pleistocene glacial variability. Apparently, the well-known shift in the period of variability during the mid-Pleistocene belies an underlying consistency in the record, that deglacial events almost always occur during times of high obliquity.

\subsection{Insolation}

Having confirmed that deglaciations occur during times of increased obliquity, it is useful to investigate the insolation pattern associated with this orbital configuration. Fig. 7 shows the diurnal average insolation contoured against latitude and day of the year, as well as the anomalies associated with maxima in obliquity and precession. Anomalies are calculated by averaging the insolation pattern at times of local maxima in obliquity (or precession) over the last $2 \mathrm{Ma}$ and then subtracting the mean insolation over the entire $2 \mathrm{Ma}$ period.

During summer months, maxima in obliquity are associated with anomalies ranging from $-2 \mathrm{~W} / \mathrm{m}^{2}$ in the tropics to $+15 \mathrm{~W} / \mathrm{m}^{2}$ at high latitudes. Positive anomalies in the annual average insolation occur at latitudes above $40^{\circ}$ and range up to $5 \mathrm{~W} / \mathrm{m}^{2}$. The redistribution of insolation caused by obliquity variations is small relative the mean, but are sustained, persisting for $\sim 10 \mathrm{Ka}$. For comparison, consider that glacial terminations involve approximately $5 \times 10^{15} \mathrm{Kg}$ of ice melting per year (Fairbanks, 1989). If the ice is assumed to initially be at $-20^{\circ} \mathrm{C}$, the energy required for melting is equivalent to $1 \mathrm{~W} / \mathrm{m}^{2}$ distributed over the Earth's surface above $50 \mathrm{~N}$. Thus, from a simple energetics point of view, even a small imbalance in net incoming radiation can account for deglaciations.

Precession is often described as a stronger control on insolation variability than obliquity. Indeed, diurnal average insolation anomalies associated with precession reach up to $30 \mathrm{~W} / \mathrm{m}^{2}$ at high Northern Hemisphere latitudes, roughly twice that of obliquity. But these highlatitude positive anomalies occur only during May and June and are compensated by equally large negative anomalies during August and September. Thus the influence of precession on the insolation integrated over the summer period can be quite small (see Huybers, 2006). Whether the seasonal redistribution of insolation associated with precession can help trigger a deglaciation remains an open question probably best addressed using coupled ice-sheet-climate models.

\subsection{Obliquity cycle skipping}

So far discussion has focused on the timing of deglacial events, but it is also useful to consider when deglacial events do not occur. During the early Pleistocene, deglacial events generally occur every obliquity cycle, but there are important exceptions where an obliquity cycle is skipped, most notably during Marine Isotope Stage 36 at $1.2 \mathrm{Ma}-$ an event previously noted as being anomalous in $\delta^{18} \mathrm{O}$ (Mudelsee and Schulz, 1997) and Chinese Loess records (Heslop et al., 2002). Near 1.6 and $1.8 \mathrm{Ma}$ obliquity maxima are associated with weak deglacial events, also giving $\sim 80 \mathrm{Ka}$ variability. These long glacial cycles are identifiable in the individual $\delta^{18} \mathrm{O}$ records (Figs. 1 and 2). Long cycles at 1.6 and $1.2 \mathrm{Ma}$ are found in all six of the $\delta^{18} \mathrm{O}$ records spanning this interval. The $1.8 \mathrm{Ma}$ event is more ambiguous, appearing in only three of the four benthic records and not the planktic record.

Cycle skipping is more frequent during the late Pleistocene, where most deglacial events are separated by two $(80 \mathrm{Ka})$ or three $(120 \mathrm{Ka})$ obliquity cycles. But here too there are exceptions. Near 0.7 and $0.6 \mathrm{Ma}$ deglacial events occur more nearly every $40 \mathrm{Ka}$. As opposed to a distinct transition from short- to long-period glacial variability, the overall impression is of a progression toward increased obliquity cycle skipping. 

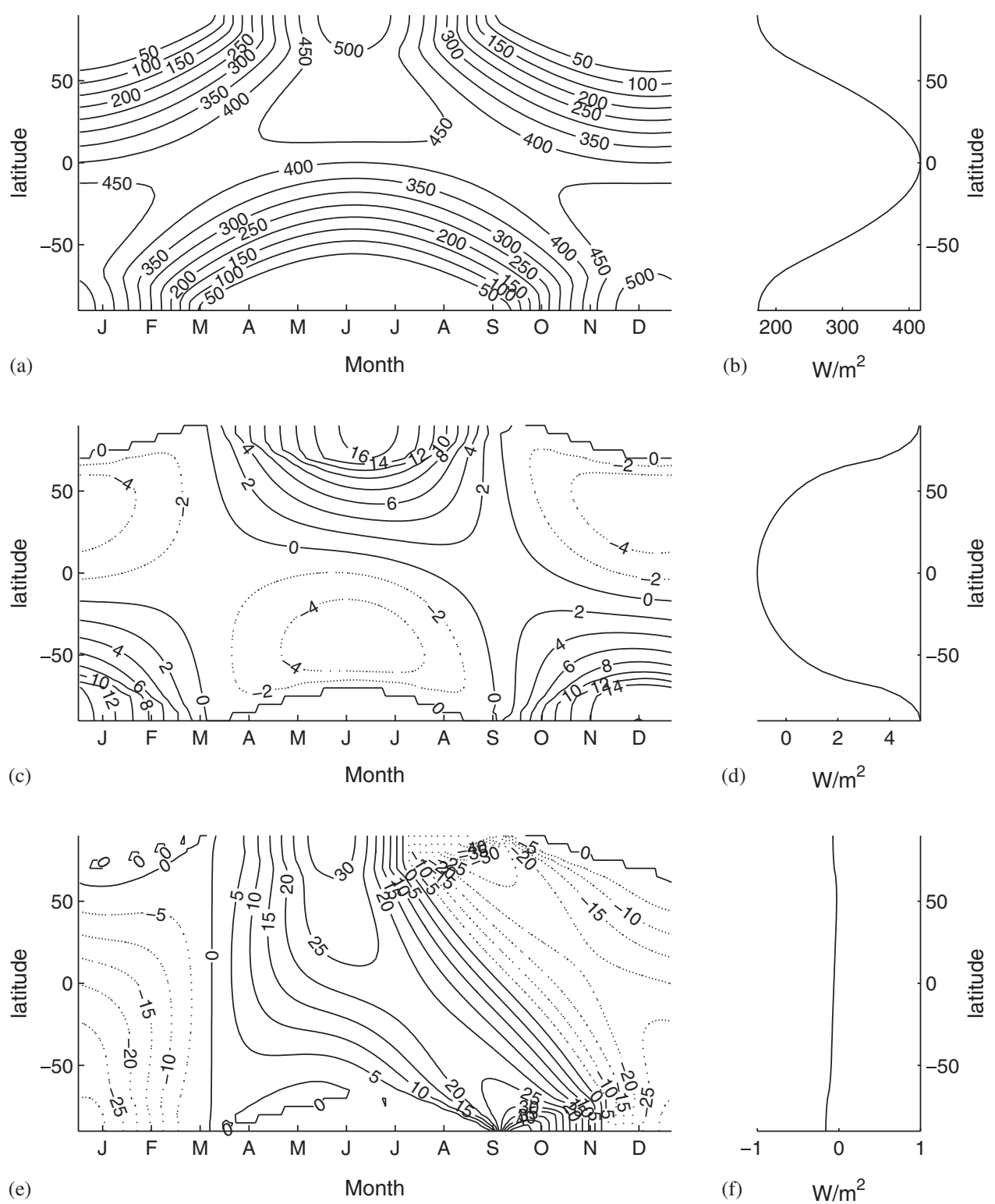

Fig. 7. Incoming insolation at the top of the atmosphere computed using the orbital solution of Berger and Loutre (1992). (a) Insolation in $\mathrm{W} / \mathrm{m}^{2}$ contoured as a function of latitude and day of the year and (b) the annual average insolation. Plots (a,b) represent average conditions over the last 2 Ma. (c) Insolation averaged during each maxima of obliquity during the last $2 \mathrm{Ma}$ and contoured as an anomaly from average conditions, along with (d) the anomaly in the annual average. (e) Insolation anomaly during maximum precession (when Earth is closest to the sun during summer solstice), and (f) the annual average showing negligibly small changes. Negative insolation anomalies are indicated by dotted contours.

There does not appear to be any systematic relationship between the time when obliquity beats are skipped and the amplitude of the obliquity cycles. Of the skipped obliquity cycles, half are associated with larger than average amplitude cycles and half with smaller amplitude cycles (see Fig. 4). It thus appears that deglaciations occur during increased obliquity, but obliquity cycle skipping arises from internal climatic factors. For the precession parameter, terminations are seen to initiate when eccentricity (and hence precession variability) is near zero at 0.8 and $0.4 \mathrm{Ma}$ as well as for the most recent termination. This result indicates that large values of the precession parameters are not required for initiation of a deglaciation.

\section{The Pleistocene progression}

The $\sim 100 \mathrm{Ka}$ glacial cycles have generally been viewed as a mode of climate variability distinct from the $40 \mathrm{Ka}$ variations (Hays et al., 1976; Maasch and Saltzman, 1990; Imbrie et al., 1992; Tziperman and Gildor, 2003). In the absence of any change in the external forcing (Pisias and Moore, 1981), the onset of $\sim 100 \mathrm{Ka}$ variations has been taken to mark the presence of an internal climatic transition (Shackleton et al., 1988; Ruddiman et al., 1989; Birchfield and Ghil, 1993; Park and Maasch, 1993; Tiedemann et al., 1994; Bolton and Maasch, 1995; Mudelsee and Schulz, 1997). In keeping with this view, modeling studies have invoked a transition - or equivalently a bifurcation - to 
describe the early and late Pleistocene glacial variability (Maasch and Saltzman, 1990; Matteucci, 1990; Paillard, 1998; Tziperman and Gildor, 2003; Ashkenazy and Tziperman, 2004). A bifurcation implies the sudden appearance of a qualitatively different mode of variability for a nonlinear system (e.g. Strogatz, 1994).

There are three lines of evidence suggesting that a single bifurcation does not adequately describe events in and around the mid-Pleistocene. The first argument follows from the presence of $80 \mathrm{Ka}$ glacial cycles prior to the midPleistocene at 1.6 and $1.2 \mathrm{Ma}$ and $40 \mathrm{Ka}$ glacial cycles as late as $0.6 \mathrm{Ma}$. Because long-period glacial cycles are present during the early Pleistocene, there can be no single transition to long-period variability. One can invoke the presence of multiple bifurcations, or the influence of stochastic processes causing temporary bifurcations, but the explanatory power of such a description is limitedwhat series of event could not be described as a set of bifurcations?

A second line of evidence has to do with regional climate shifts. If the climate system underwent a bifurcation with respect to glacial variability, it seems that other elements of the system would show a contemporaneous shift. Conversely, gradual changes in the other components or asynchronous shifts are more difficult to rationalize as owing to a single bifurcation.

Ravelo et al. (2004) examined climate records from high latitudes, the subtropics, and tropics and concluded that the onset of glacial variability $\sim 2.7 \mathrm{Ma}$ does not coincide with a reorganization at low latitudes. A similar conclusion appears to hold for the mid-Pleistocene, near $0.8 \mathrm{Ma}$. Slow cooling of the deep oceans appears to have completed prior to $1 \mathrm{Ma}$ (Billups, 1998; McIntyre et al., 1999; Marlow et al., 2000). The $\delta^{13} \mathrm{C}$ of North Atlantic intermediate depth water, indicative of nutrient cycling and ocean transport, appears to be stable over the Pleistocene (Raymo et al., 2004). At lower latitudes, $\delta^{13} \mathrm{C}$ are reported to become more negative near $1 \mathrm{Ma}$, but then return to early-Pleistocene value by $0.4 \mathrm{Ma}$ (Raymo et al., 1997). African aridity seems to increase gradually with a transition, if anywhere, near $1.4 \mathrm{Ma}$ (DeMenocal, 1995). Chinese loess deposits show a transition to greater variability in mean grain size at $1 \mathrm{Ma}$ and in magnetic susceptibility at $0.6 \mathrm{Ma}$ (Heslop et al., 2002). Both seasonal upwelling along the California margin and the East-West $\delta^{18} \mathrm{O}$ gradient across the tropical Pacific shows an increase near $1.7 \mathrm{Ma}$ (Ravelo et al., 2004). The Western Equatorial Pacific has approximately stable average surface temperatures over the last $5 \mathrm{Myr}$ (Wara et al., 2005), with an increase in the period and amplitude of variability at $0.5 \mathrm{Ma}$ (Medina-Elizalde and Lea, 2005). The Eastern Equatorial Pacific shows a cooling trend over the last 1.5 Ma (Liu and Herbert, 2004; Wara et al., 2005).

As is true for nearly all geophysical measurements, Pleistocene climate records show variability at all times and timescales. Transitions and changes in different component of the climate system occur continuously over the last $2 \mathrm{Ma}$, and the mid-Pleistocene does not appear especially anomalous. Also note that the phasing of Equatorial Pacific surface temperatures relative to ice-volume variations appears to be stable over the entire Pleistocene (Medina-Elizalde and Lea, 2005), indicating an invariant relationship between high- and low-latitude climate variability.

The final line of evidence for a gradual rather than sudden transition relies upon the evolution of the statistical properties of the $\delta^{18} \mathrm{O}$ stack. The analysis of the stack is complementary to the examination of numerous regional climate records in that the stack reflects aggregate changes in both ice volume and temperature. Ice-volume variations are nearly anti-phased with temperature variations in the tropics (Liu and Herbert, 2004; Medina-Elizalde and Lea, 2005) and at high latitudes (Blunier et al., 1998). This antiphased behavior is conveniently monitored by the $\delta^{18} \mathrm{O}$ of foraminiferal calcite because greater ice volume and lower temperatures both serve to increase $\delta^{18} \mathrm{O}$ values. Furthermore, because the agemodel is not orbitally tuned, the stack permits analysis of changes in orbital period variability over the last $2 \mathrm{Ma}$ without relying on orbital assumptions.

\subsection{Average frequency}

Most studies identify the onset of $\sim 100 \mathrm{Ka}$ variability near $0.8 \mathrm{Ma}$ as indicating a transition from one mode of glacial variability to another (e.g. Shackleton et al., 1988; Ruddiman et al., 1989; Park and Maasch, 1993; Bolton and Maasch, 1995; Mudelsee and Schulz, 1997). The obliquity pacing results, however, indicate that the $\sim 100 \mathrm{Ka}$ variability is not a pure mode, but is rather derived from the skipping of obliquity beats. Thus, focusing on the $\sim 100 \mathrm{Ka}$ band to the exclusion of other frequencies is too narrow a definition to accurately quantify Pleistocene trends in glaciation.

An analogy can be made with the sirens of a passing fire truck. Owing to Doppler shifting of the sound waves, the sirens will sound at increasingly low frequencies. If the presence of the fire truck was only gauged by monitoring a single frequency, one might wrongly conclude that it appeared from nowhere.

A quantity better able to describe the evolution of the glacial cycle frequency is the first moment of the spectrum, $M_{1}=P^{-1} \times \sum_{i=1}^{N} p_{i} \times s_{i}$. Here, $p_{i}$ is the power density at the $i$ th frequency band associated with a central frequency $s_{i}$, and $P$ is the sum of the power at all the bands. The quantity $M_{1}$ indicates the average frequency of the variability. Only frequencies below $\frac{1}{15} \mathrm{Ka}$ are considered as the higher frequency variability is damped by smoothing and averaging of the $\delta^{18} \mathrm{O}$ records.

The evolution of statistical quantities is estimated using a $200 \mathrm{Ka}$ rectangular sliding window. Conclusions are unchanged if a longer window is used; a longer window makes results less noisy but provides fewer independent 


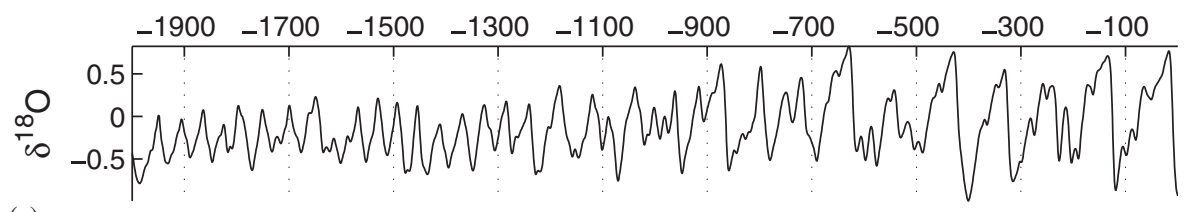

(a)

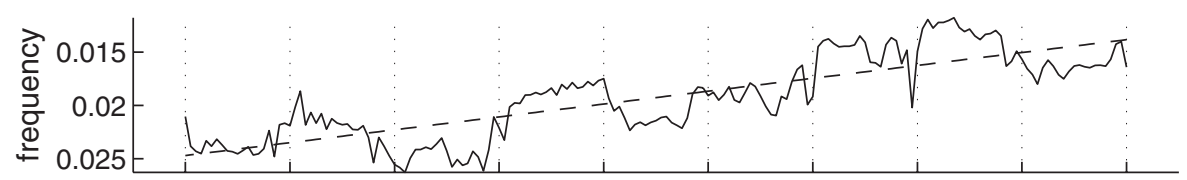

(b)

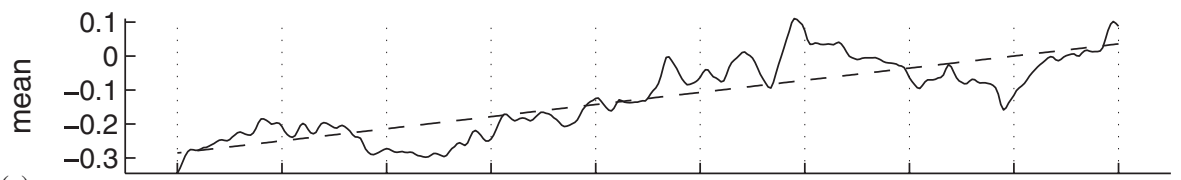

(c)

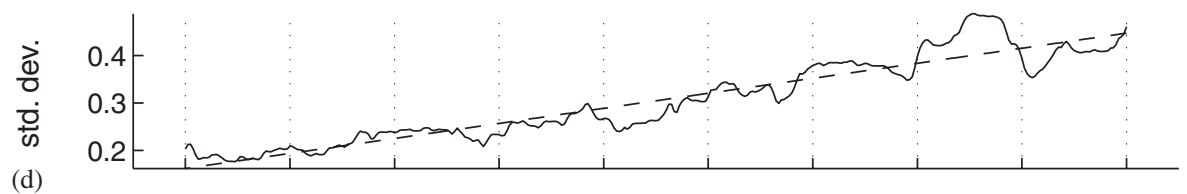

(d)

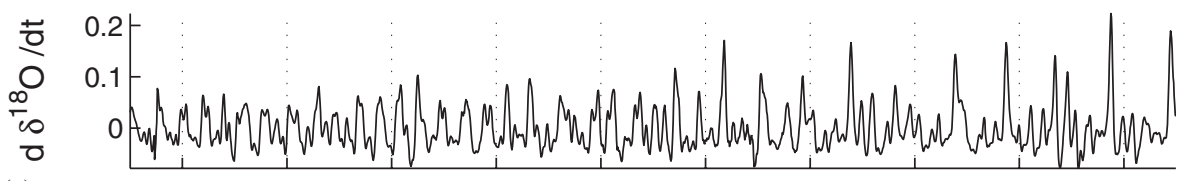

(e)
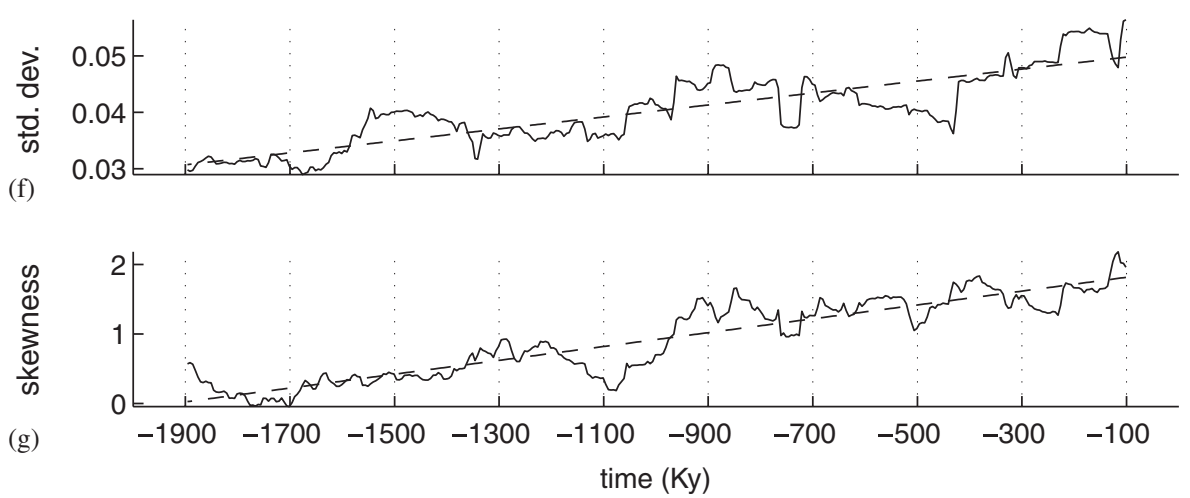

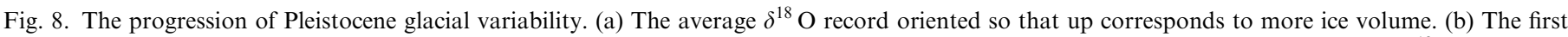

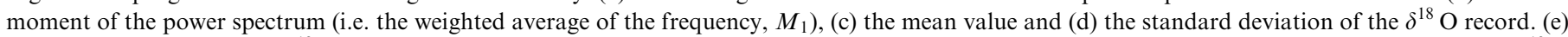

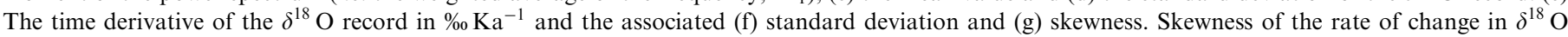

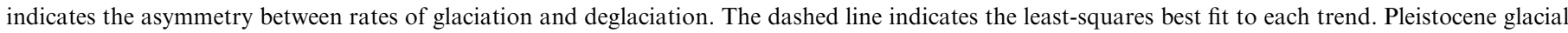

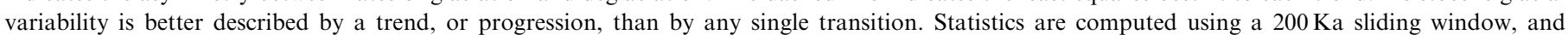
independent realizations of each statistic are indicated by the vertical dotted lines.

realizations and would broaden any abrupt features. Shorter windows introduce serious aliasing of the $\sim 100 \mathrm{Ka}$ glacial cycles and thus are not easily interpreted.

Fig. 8b shows that $M_{1}$ follows an approximately linear trend, beginning at the $\frac{1}{40} \mathrm{Ka}$ frequency $2 \mathrm{Ma}$ and evolving to a lower $\frac{1}{70} \mathrm{Ka}$ frequency. Such a trend is evident in the evolutionary spectrum (Fig. 4) and agrees with the increasing number of skipped obliquity cycles (Fig. 5). Were this trend to continue, glacial cycles lasting $160 \mathrm{Ka}$ would presumably appear.

\subsection{Mean and variance}

Long-term trends are also evident in the average $\delta^{18} \mathrm{O}$, associated with increased ice volume (Raymo, 1994) and ice-volume variability. The $\delta^{18} \mathrm{O}$ maximum near $0.9 \mathrm{Ma}$ (stage 22), the largest seen up to that time, has generally been identified with a glacial transition (Prell, 1982; Maasch, 1988; De Blonde and Peltier, 1991; Berger and Jansen, 1996; Mudelsee and Schulz, 1997). But it can also be argued that the glacial maxima at $1.2 \mathrm{Ma}$ (stage 36 ) and 
possibly at $0.6 \mathrm{Ma}$ (stage 16) represent unprecedented increases in $\delta^{18} \mathrm{O}$ which are associated with transitions toward longer period variability.

Rather than speaking of a series of independent transitions, it is probably more useful to describe these events as a trend. Fig. $8 \mathrm{c}$ shows the mean computed using a sliding $200 \mathrm{Ka}$ window, giving 10 independent realizations of the mean value. Changes in the mean value show the most step-like transition of any quantity investigated, but even here a linear trend is the best order-one description. The residual variance after removing the best-fit trend from the 10 independent realizations of the mean is $(0.076 \%)^{2}$, somewhat smaller than if the best-fit step wise transition is removed $(0.082 \%)^{2}$.

Mudelsee and Schulz (1997) note that changes in the mean value preceded the onset of $\sim 100 \mathrm{Ka}$ variability, and describe this as an unexplained feature of the Pleistocene variability. Here, a simple explanation is offered, that increases in the mean $\delta^{18} \mathrm{O}$ value do occur concomitant with increases in the period, but that the identification and comparison of particular transition times is an inappropriate description of the variability.

The standard deviation shows a more linear trend than the mean (Fig. 8d). The trend toward lower frequency variability and a greater standard deviation may have a simple relationship to one another. For example, in the simple linear system $\mathrm{d} x / \mathrm{d} t=\sin w t$ the amplitude of the oscillations in $x$ are inversely proportional to the frequency, $w$. The amplitude of the derivative of $x$, however, is insensitive to the forcing period, making it interesting to explore the time rate of change in $\delta^{18} \mathrm{O}$ (Fig. 8e). Fig. 8f shows that a trend toward increasing standard deviation exists even in the time rate of change in $\delta^{18} \mathrm{O}$. This indicates that the trend toward lower frequencies is not alone sufficient to explain the greater amplitude of variability. The implication is that the climatic sensitivity to external forcing and/or internal variability has increased through time.

Ravelo et al. (2004) have considered the sensitivity of glacial variability to obliquity forcing. Sensitivity appears to increase between 4 and $1 \mathrm{Ma}$, but then declines toward the present, seemingly at odds with the above interpretation of continuous obliquity pacing and a continuous increase in sensitivity. The difference in interpretation arises because of the narrow versus broad-band analysis of the variability. Ravelo et al. (2004) assume a linear relationship between the obliquity forcing and the climatic response. Similarly, Lisiecki and Raymo (in press) interpret the climate response to orbital forcing within the context of a linear relationship. Here, it is argued that the response to obliquity became increasingly nonlinear, resulting in greater variability at periods other than $40 \mathrm{Ka}$. If variations with 40,80 , and $120 \mathrm{Ka}$ periods are all considered as related to obliquity, a positive trend is obtained in sensitivity over the last $2 \mathrm{Myr}$, similar to the trend in standard deviation (Fig. 8d).

Note that the interpretation of glacial variability as the forced response to insolation variability is but one possibility. Another possibility is that glacial cycles are a free mode of variability but which is phase-locked by the insolation forcing (Saltzman et al., 1984; Tziperman et al., in press). In this case, the timing of glacial variability may be controlled by obliquity but the amplitude of the variability would be largely independent.

\subsection{Asymmetry}

A final quantity of interest is the skewness of the rate of change in $\delta^{18} \mathrm{O}$, a measure of the asymmetry between accumulation and ablation. Over the course of the Pleistocene a nearly linear trend is present from zero skewness to increasingly large values (Fig. 8g). This indicates that deglaciations became increasingly rapid relative to ice-sheet growth. The presence of asymmetry in the glacial cycles agrees with the results of Raymo (1992) and Ashkenazy and Tziperman (2004). The existence of a trend in the asymmetry is also consistent with finding of Lisiecki and Raymo (in press).

One complexity arises in that sediment composition or accumulation rates may covary with other climate changes (Herbert, 1994). For instance, if the average rate of accumulation was to decrease during deglaciation, age estimates would be compressed with deglaciations appearing more rapid and glacial cycles more asymmetric. The most recent glacial cycles are known to be highly asymmetric because the rate of climate change can be found using radiometric techniques (e.g. Thompson and Goldstein, 2005) or annual layer counts (e.g. Meese et al., 1997). These climate-independent dating techniques, however, are not applicable beyond a few hundred-thousand years ago, making inferences regarding the more subtle early-Pleistocene asymmetry more circumspect.

Taking the observations at face value, asymmetric variability indicates that a purely linear response to the Milankovitch forcing is an insufficient explanation of the early-Pleistocene glacial variability. Numerous explanations have been put forward for the asymmetry between rates of glaciation and deglaciation including the interaction between accumulation and isostatic rebound (LeTreut and Ghil, 1983), ice-sheet instabilities (Pollard, 1983; Marshall and Clark, 2002), decreases in the albedo of aging snow (Galleé et al., 1992), and changes in accumulation caused by rapid expansion of sea ice (Tziperman and Gildor, 2003). There appears no fundamental reason why any of these physical mechanisms could not evolve gradually. For example, while the extent of sea ice in the North Atlantic sector does change rapidly on a seasonal basis, a long-term cooling trend could serve to gradually increase the amplitude of these changes.

Lisiecki and Raymo (in press) have examined trends in a different compilation of $\delta^{18} \mathrm{O}$ records (Lisiecki and Raymo, 2005), and come to similar conclusions that there exist gradual trends toward greater ice volume, variance, and skewness through time and that the mid-Pleistocene is not marked by any distinct transition. Taken together, the 
gradual trend in glacial cycle variability and continuous obliquity pacing indicate that Pleistocene glacial variability is better described by a progression than by any single transition.

\section{A simple model}

To describe the Pleistocene progression in glacial variability the simple model of the data presented in HW05 is extended to include a temporal trend,

$V_{t}=V_{t-1}+\eta_{t}$ and if $V_{t} \geqslant T_{t}$ terminate,

$T_{t}=a t+b-c \theta_{t}^{\prime}$.

Here $V$ is ice volume in normalized units, $t$ is time, $\eta_{t}$ represents the balance of accumulation and ablation over one time step, and $T_{t}$ is a time-variable threshold consisting of a linear trend modulated by obliquity, $\theta^{\prime}$. The prime indicates that obliquity is normalized to zero mean and unit variance. Ice volume is parameterized to accumulate through time until the threshold condition is crossed, invoking a termination which linearly resets ice volume to zero over $10 \mathrm{Ka}$. The model describes a simple limit cycle consisting of steady accumulation followed by rapid collapse, a behavior which has been produced by more sophisticated ice-sheet models (Marshall and Clark, 2002). The obliquity modulation of the threshold condition may be rationalized in that increased annual average highlatitude insolation could heat an ice-sheet, increasing melting and lubrication of the ice-sheet base, and increasing the likelihood of a collapse (HW05).

There are only three adjustable parameters associated with Eq. (3), each associated with the threshold condition: the slope (a), intercept (b), and obliquity amplitude (c). Net accumulation is set to $\eta=1$; adjustments in this parameter can equivalently be made by changing the threshold conditions. Unlike the model presented in HW05, this model is insensitive to initial conditions because the termination condition always resets ice volume to zero near the beginning of the model run. Selecting a slope of $a=0.05 \mathrm{Ka}^{-1}$, an intercept of $b=126$, and an obliquity amplitude of $c=20$ reproduces the timing of most deglaciations over the last $2 \mathrm{Ma}$ (see Fig. 9a). Exceptions are that a deglaciation near $1.35 \mathrm{Ma}$ is missed, the long glacial cycle at $1.6 \mathrm{Ma}$ is not reproduced, termination 3 initiates $10 \mathrm{Ka}$ too early, and some of the smaller late-Pleistocene deglaciations are not reproduced. One other shortcoming is that while the amplitudes of the late-Pleistocene deglaciation are reproduced, the earlyPleistocene variations are too small. The inclusion of a

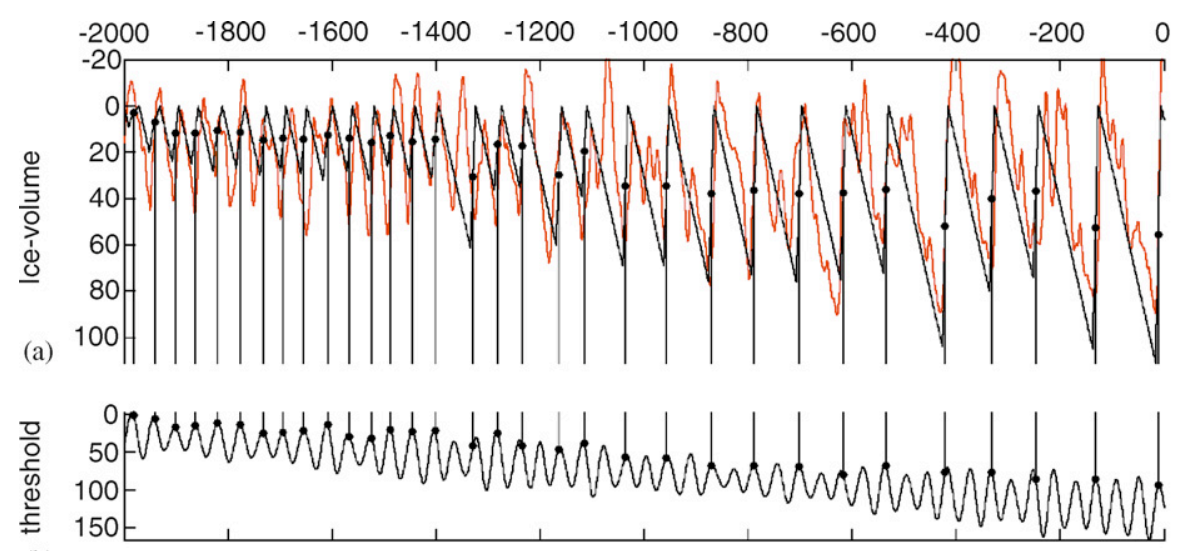

(b)

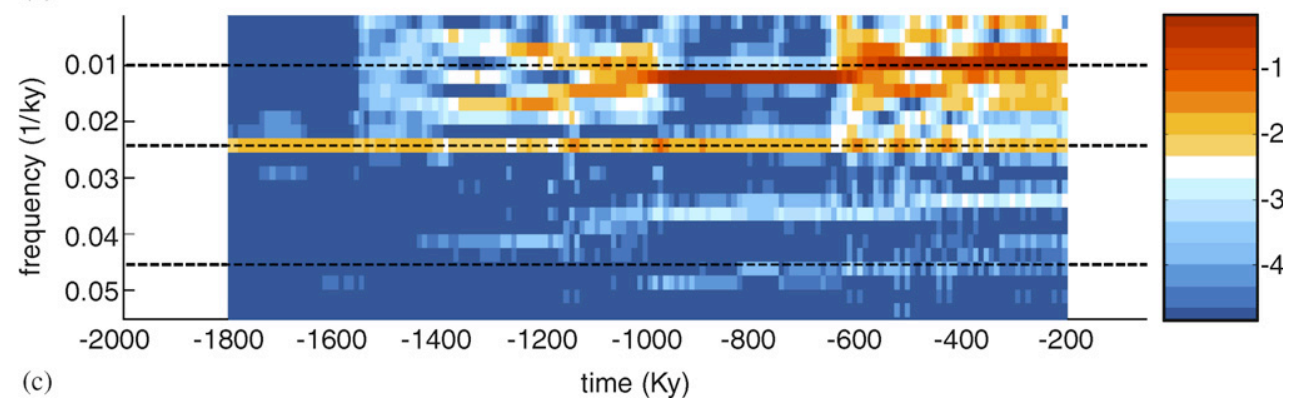

Fig. 9. Results from the simple model given in Eq. (3). (a) Model output is plotted against the $\delta^{18} \mathrm{O}$ stack on the depth-derived agemodel. (b) Model threshold having a linear trend with superimposed obliquity variability. Vertical lines indicate the mid-point of each termination and always occur near maximum obliquity $(R=0.9)$. After tuning the model's three adjustable parameters (see text), it describes the timing of most deglaciations. (c) At bottom is an evolutionary spectral estimate of the model results. Shading indicates the logarithm of the power density (in units $\left.{ }^{2} / \mathrm{cycle}_{\mathrm{K}} / \mathrm{Ka}\right)$ as a function of time (Ka) and frequency $(1 / \mathrm{Ka})$. Horizontal lines are at $\frac{1}{100}$, $\frac{1}{41}$, and $\frac{1}{22} \mathrm{Ka}$. Similar to the spectrogram of the $\delta^{18} \mathrm{O}$ stack (Fig. 4), energy is concentrated at the obliquity period during the late Pleistocene, but with increasing obliquity beat skipping and asymmetry between glaciation and ablation rates, concentrations of power appear at $\frac{1}{100}$ and $\frac{1}{22} \mathrm{Ka}$ bands. Horizontal dashed lines indicate the $\frac{1}{100}, \frac{1}{41}$, and $\frac{1}{22} \mathrm{Ka}$ frequencies. 
more complicated threshold condition or additional modulation of the accumulation rate by orbital variations could improve the model fit with the observations, but at the expense of making the model more complicated.

One insight obtained from Eq. (3) pertains to why the mid-point of each termination occurs near maximum obliquity. The initiation of a model termination generally occurs while obliquity is large but still increasing, i.e. before maximum obliquity. Because the duration of a termination is $\sim 10 \mathrm{Ka}$, the termination mid-point occurs $5 \mathrm{Ka}$ after its initiation, typically in the vicinity of maximum obliquity. The mean phase of obliquity during deglaciations is $6 \pm 23^{\circ}$, and the Rayleigh's $R$ value is 0.9 , indicating a high degree of phase stability.

An evolutionary spectrum of the model output (Fig. 9c) shows that it reproduces the main spectral features associated with the $\delta^{18} \mathrm{O}$ record (Fig. 4). Spectral energy remains nearly constant at the $40 \mathrm{Ka}$ period. (More precisely, the obliquity period is at $41 \mathrm{Ka}$.) Growth of energy is seen at periods longer than obliquity near $1.4 \mathrm{Ma}$ and culminates in strong $\sim 100 \mathrm{Ka}$ power by $0.5 \mathrm{Ma}$. Energy at $\sim 22 \mathrm{Ka}$ periods appears near $1 \mathrm{Ma}$ and remains up to the present. Importantly, this change in model spectral characteristics occurs without any sudden change in the mode of glacial variability. The gradual increase in the threshold value causes glacial cycles to more often skip obliquity beats and accounts for the increase in lowfrequency variability. Likewise, the increasing threshold value causes the deglaciation to become increasingly rapid and increases the asymmetry of the glacial cycles. Such asymmetry in a time-series introduces overtones and harmonics in the Fourier spectrum (e.g. Bracewell, 2000) and accounts for the appearance of an overtone of the obliquity period near $\frac{2}{40}=\frac{1}{20} \mathrm{Ka}$ and a combination tone at $\frac{1}{100}+\frac{1}{40} \sim \frac{1}{29} \mathrm{Ka}$. Note that the concentration of variability at the $29 \mathrm{Ka}$ period in the model output is not found in the $\delta^{18} \mathrm{O}$ stack, but has been identified in other studies of $\delta^{18} \mathrm{O}$ variability (Yiou et al., 1991; Bolton and Maasch, 1995; Mix et al., 1995b; HW04).

The addition of a stochastic component to the model simulates the presence of weather at the highest frequencies and the myriad climatic processes not resolved by the model at longer periods (see Wunsch, 2004). Here a stochastic component is parameterized by changing the accumulation term, $\eta_{t}$, in Eq. (3) from a constant to a random realization from a normal distribution with a mean and standard deviation of one. The timing of deglaciation is still controlled by obliquity (Rayleigh's $R$ averages $0.75 \pm 0.2$ ), but obliquity cycle skipping is now random so that the glacial sequence need not coincide with the $\delta^{18} \mathrm{O}$ stack.

Even with the stochastic forcing, the model reproduces the progression in statistical quantities described in Section 4. By selecting a positive slope for the threshold value, ice volume and its variance will increase through time. The fixed rate of accumulation coupled with an increasing threshold makes the average glacial cycle frequency decrease. Furthermore, because ice volume is always made to decrease to zero in a $10 \mathrm{Ka}$ period, the asymmetry between rapid deglaciation and slow accumulation will increase through time, in agreement with the trend toward greater skewness in the rate of change of $\delta^{18} \mathrm{O}$. A typical realization of the stochastic model and the evolution of its period, mean, variability, and skewness are shown in Fig. 10. Trends are very similar to those observed for the stack and occur for a wide range of parameterizations and noise conditions.

A number of other simple models have been used to describe Pleistocene glacial variability (e.g. Paillard, 1998; Clark et al., 1999; Tziperman and Gildor, 2003). Each of these models relates the $\sim 100 \mathrm{Ka}$ variability to the precession forcing. A troublesome feature of these models is that the early-Pleistocene variability shows significant $\sim 22 \mathrm{Ka}$ precession period variability, at odds with the $\delta^{18} \mathrm{O}$ data. This suggests that a model relying upon precession to generate the $\sim 100 \mathrm{Ka}$ period will, in general, have difficulty generating predominantly $40 \mathrm{Ka}$ period variability during the early Pleistocene. Models relying upon $40 \mathrm{Ka}$ variations to pace the $\sim 100 \mathrm{Ka}$ glacial cycles should more readily reproduce the early-Pleistocene $40 \mathrm{Ka}$ variations.

The study by Ashkenazy and Tziperman (2004) compared their model results against the $\delta^{18} \mathrm{O}$ proxy of glacial variability. The model achieves a maximum cross-correlation with the $\delta^{18} \mathrm{O}$ record of 0.3 when the $\delta^{18} \mathrm{O}$ agemodel is not tuned to orbital variability and 0.5 when the agemodel is tuned. Their model has eight adjustable parameters including a switch near 0.9 Ma. By comparison, the model given in Eq. (3) has only three adjustable parameters and achieves a cross-correlation of 0.7 with the $\delta^{18} \mathrm{O}$ stack. That Eq. (3) has fewer adjustable parameters and obtains a higher cross-correlation indicates a more skillful description of the Pleistocene glacial variability.

The simplicity of Eq. (3), however, is such that the longterm trend in the threshold value could arguably be identified with a number of independent processes. Candidates are a long-term decrease in greenhouse gases (Raymo, 1997) causing global cooling and the ability to sustain larger ice-sheets. A related possibility is that global cooling effects deep ocean temperature and sea-ice variability (Tziperman and Gildor, 2003). Another candidate is scouring of the continental regolith (Clark et al., 1999) causing greater friction between the ice-sheet and its bed and permitting the accumulation of greater continental ice volume. While rationalizations can be offered to relate the trend in the threshold to physical mechanisms, the analysis presented here is incapable of distinguishing between mechanisms. A more physical model of the glacial cycles will be required to distinguish the controls on the long-term evolution of the glacial cycles.

\section{Further discussion and conclusions}

The Pleistocene has generally been described as having two distinct modes of glacial variability characterized by 40 and $\sim 100 \mathrm{Ka}$ periods of variability. Indeed, the early 


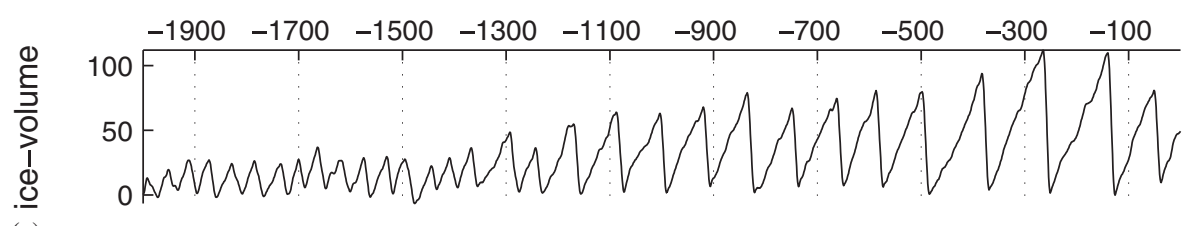

(a)

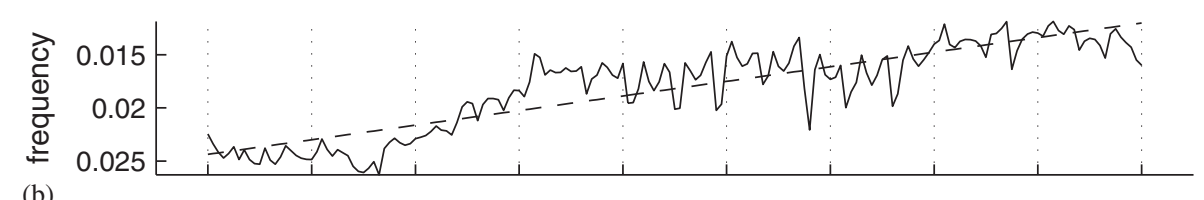

(b)
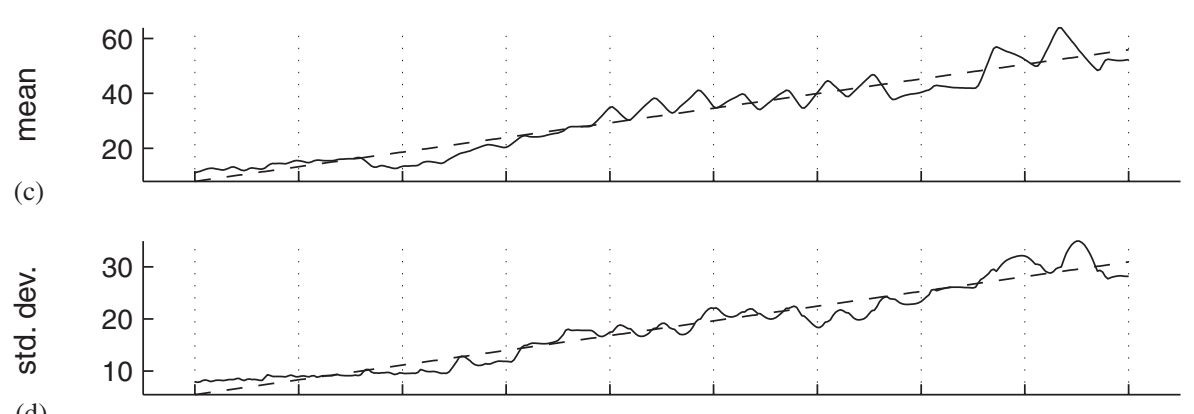

(d)

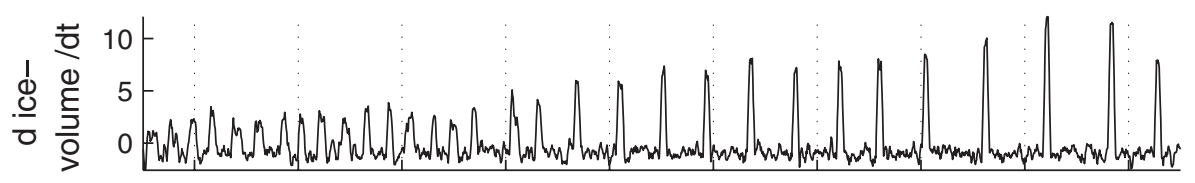

(e)
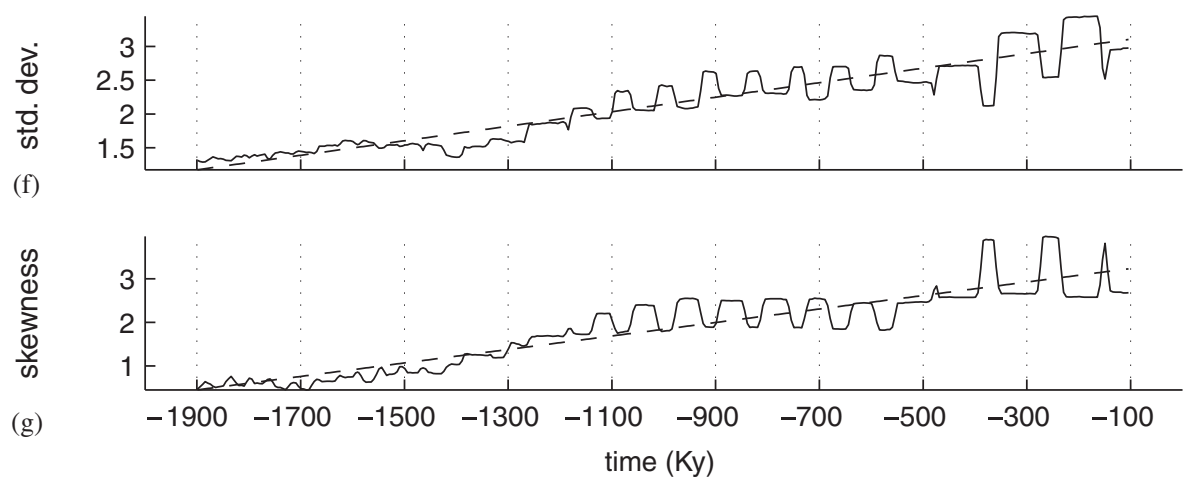

Fig. 10. Statistical evolution of a realization of Eq. (3) using the stochastic accumulation parameterization. Results are similar with those of the $\delta^{18} \mathrm{O}$ stack (see Fig. 8). (a) Typical realization of the model output. Units are in normalized ice volume. (b) Weighted average of the frequency ( $M_{1}$, see text), (c) mean value, and (d) standard deviation of the model ice volume. (e) The rate of change in ice volume and the evolution of the associated (f) standard deviation and (g) skewness. All statistics generally follow a linear trend as indicated by the dashed line.

Pleistocene has been called Milankovitch's other unsolved mystery (Raymo and Nisancioglu, 2003). The continuous obliquity pacing of deglaciations, however, indicates that both the early- and late-Pleistocene glacial cycles derive from similar mechanisms and that there is but a single Pleistocene glacial mystery. A physical model capable of generating $40 \mathrm{Ka}$ variability during the early Pleistocene will probably also explain the $\sim 100 \mathrm{Ka}$ variations of the late Pleistocene.

Continuous obliquity pacing of the Pleistocene glacial variability is a more simple hypothesis than those calling upon a new mode of variability to explain the $\sim 100 \mathrm{Ka}$
late-Pleistocene variability. The obliquity hypothesis also resolves or side steps many of the problems facing the conventional orbital theory of the glacial cycles. To highlight this point, the major problems associated with the orbital theory (following the list of Elkibbi and Rial, 2001) are listed and addressed below:

(1) The $\sim 100 \mathrm{Ka}$ variations in insolation forcing due to eccentricity changes are too small to directly cause the glacial cycles (Imbrie et al., 1993): The results of the hypothesis test (Section 2) indicate that eccentricity does not pace the glacial cycles. 
(2) The $\delta^{18} \mathrm{O}$ data do not show a $413 \mathrm{Ka}$ period, corresponding to the most energetic eccentricity band of variability (Imbrie et al., 1993): Again, the period of glacial variability is unrelated to eccentricity.

(3) The mid-Pleistocene transition occurs without a corresponding change in the insolation forcing (Pisias and Moore, 1981): Pleistocene glaciation undergoes a gradual evolution unrelated to changes in the insolation forcing.

(4) Glacial cycles vary in duration from $\sim 80$ to $\sim 120 \mathrm{Ka}$ during the last pleistocene (Raymo, 1997; Petit et al., 1999): This supports the obliquity pacing hypothesis which calls on glacial cycles to be quantized in multiples of the basic $40 \mathrm{Ka}$ period.

(5) Spectral peaks exist at frequencies other than those in the insolation forcing (Nobes et al., 1991; Bolton and Maasch, 1995; HW04): This can be explained by the obliquity cycle skipping and the asymmetry between rates of deglaciations and accumulation (see Section $4.3)$. Note that much of the variability resides at nonorbital periods indicating the presence of a significant stochastic contribution (Wunsch, 2004) or a significantly nonlinear response to the insolation forcing (Huybers and Curry, 2006).

(6) A final issue, not discussed by Elkibbi and Rial (2001), is that the glacial cycles are symmetric between the hemispheres whereas the seasonal precession forcing is anti-symmetric: This is readily addressed in that the annual average and seasonal insolation anomalies caused by changes in obliquity are, like the glacial cycles, symmetric between the hemispheres (see Section $3.5)$.

A related issue, touched in item (3), is that the transition from 40 to $\sim 100 \mathrm{Ka}$ modes of glacial variability has generally been described as rapid relative to the duration of the Pleistocene. This view derives from the sudden onset of $\sim 100 \mathrm{Ka}$ variability. But because the $\sim 100 \mathrm{Ka}$ variability is not a fundamentally new mode of variability, a more general description of the variability is required. Examination of the evolution of the mean value, variance, average period, and asymmetry of the glacial cycles all indicate that the variability slowly evolves over the course of the Pleistocene.

A succinct description of Pleistocene glacial variability is codified in Eq. (3) using only three adjustable parameters. In words, ice tends to accumulate until some threshold is reached, causing a deglaciation. The threshold level is modulated by obliquity and exhibits a long-term trend. The modulation causes terminations to occur near maxima in obliquity while the trend causes an increase in the mean, variance, asymmetry, and period of the ice-volume variability. The model exhibits a gradual progression in its qualitative behavior rather than a bifurcation. That Eq. (3) reproduces the primary structure of the glacial variability indicates that obliquity pacing alone is a sufficient description of Pleistocene glaciation.
Analysis of the $\delta^{18} \mathrm{O}$ record provides important clues and constraints regarding the nature of the glacial variability, but is insufficient to uniquely determine the causes of the glacial cycles. Major uncertainties remain regarding the Pleistocene glacial variability, including the origins of the progression in the glacial cycle variability and the physical mechanisms responsible for glacial terminations. Use of more physical models of the climate variability and incorporation of a greater variety of climate proxies is essential to furthering our understanding of Pleistocene glaciation.

\section{Acknowledgments}

Funding was provided by the NOAA Postdoctoral Program in Climate and Global Change. Useful comments were provided by Tom Herbert, Kat Huybers, Maureen Raymo, Martin Tingley, and Carl Wunsch.

\section{References}

Ashkenazy, Y., Tziperman, E., 2004. Are the $41 \mathrm{kyr}$ glacial oscillations a linear response to Milankovitch forcing? Quaternary Science Reviews 23, 1879-1890.

Bahr, D., Hutton, E., Syvitski, J., Pratson, L., 2001. Exponential approximations to compacted sediment porosity profiles. Computers and Geoscience 27, 691-700.

Bassinot, F., Beaufort, L., Vincent, E., Labeyrie, L., Rostek, F., Muller, P., Quidelleur, X., Lancelot, Y., 1994. Coarse fraction fluctuations in pelagic carbonate sediments from the Tropical Indian Ocean: a 1500kyr record of carbonate dissolution. Paleoceanography 9, 579-599.

Berger, A., Loutre, M.F., 1992. Astronomical solutions for paleoclimate studies over the last 3 million years. Earth and Planetary Science Letters 111, 369-382.

Berger, W., Jansen, E., 1996. Mid-Pleistocene climate shift-the Nansen connection. In: Johannessen, O., Muench, R., Overland, J. (Eds.), The Polar Oceans and Their Role in Shaping the Global Environment, vol. 85, pp. 295-311.

Berggren, W., Hilgen, F., Langereis, C., Kent, D., Obradovich, J., Raffi, I., Raymo, M., Schackleton, N., 1995. Late Neogene chronology: New perspectives in high resolution stratigraphy. Geological Society of America Bulletin 107, 1272-1287.

Bickert, T., Curry, W., Wefer, G., 1997. Late Pliocene to Holocene (2.6-0 MA) western equatorial Atlantic deep water circulation: inferences from benthic stable isotopes. In: Shackleton, N., Curry, W., Richter, C., Bralower, T. (Eds.), Proceedings of the Ocean Drilling Program Scientific Results, vol. 154, pp. 239-253.

Billups, K., 1998. Early pliocene deep water circulation in the western equatorial Atlantic: implications for high-latitude climate change. Paleoceanography 13, 84-95.

Birchfield, G., Ghil, M., 1993. Climate evolution in the pliocene and pleistocene from marine-sediment records and simulations: internal variability versus orbital forcing. Journal of Geophysical Research D98, 10385-10399.

Blunier, T., Chappellaz, J., Schwander, J., Dallenbach, A., Stauffer, B., Stocker, B., Raynaud, D., Jouzel, J., Clausen, H., Hammer, C., Johnsen, S., 1998. Asynchrony of Antarctic and Greenland climate change during the last glacial period. Nature 394, 739-743.

Bolton, E., Maasch, K., 1995. A wavelet analysis of Plio-Pleistocene climate indicators: a new view of periodicity evolution. Geophysical Research Letters 22, 2753-2756.

Bracewell, R., 2000. The Fourier Transform and its Applications. McGraw-Hill, New York. 
Cande, S., Kent, D., 1995. Revised calibration of the geomagnetic polarity timescale for the late cretaceous and cenozoic. Journal of Geophysical Research 100 (B4), 6093-6096.

Channell, J., Hodell, D., Lehman, B., 1997. Relative geomagnetic paleointensity and $\delta^{18} \mathrm{O}$ at ODP site 983 . Earth and Planetary Science Letters 153, 103-118.

Clark, P., Alley, R., Pollard, D., 1999. Northern hemisphere ice-sheet influences on global climate change. Science 5442, 1104-1111.

Cullen, J., Curry, W., 1997. Variations in planktonic foraminifer faunas and carbonate preservation at site 927: evidence for changing surface water conditions in the Western Tropical Atlantic Ocean during the middle Pleistocene. In: Shackleton, N., Curry, W., Richter, C., Bralower, T. (Eds.), Proceedings of the Ocean Drilling Program Scientific Results, vol. 154, pp. 207-228.

Curry, W., Cullen, J., 1997. Carbonate production and dissolution in the Western Equatorial Atlantic during the last 1 MY. In: Shackleton, N., Curry, W., Richter, C., Bralower, T. (Eds.), Proceedings of the Ocean Drilling Program Scientific Results. Ocean Drilling Program, vol. 154. College Station, TX, pp. 189-199.

De Blonde, G., Peltier, W., 1991. A one-dimensional model of continental ice volume fluctuations through the Pleistocene: implications for the origin of the mid-Pleistocene climate transition. Journal of Climate 4, 318-344.

DeMenocal, P., 1995. Plio-pleistocene African climate. Science 270, 53-59.

Devore, J., 2000. Probability and Statistics for Engineering and the Sciences. Duxbury.

Elkibbi, M., Rial, J., 2001. An outsider's review of the astronomical theory of the climate: is the eccentricity-driven insolation the main driver of the ice ages? Earth-Science Reviews 56, 161-177.

Fairbanks, R., 1989. A 17,000-year glacio-eustatic sea level record; influence of glacial melting rates on the Younger Dryas event and deep-ocean circulation. Nature 342, 637-642.

Flower, B., 1999. Planktonic foraminifers from the Subpolar North Atlantic and Nordic Seas: sites 980-987 and 907. In: Raymo, M., Jansen, E., Blum, P., Herbert, T. (Eds.), Proceedings of the Ocean Drilling Program, pp. 19-34.

Galleé, H., Van Ypersele, J., Fichefet, T., Marsiat, I., Tricot, C., Berger, A., 1992. Simulation of the last glacial cycle by a coupled sectorially averaged climae-ice sheet model, 2 , response to insolation and $\mathrm{CO}_{2}$ variations. Journal of Geophysical Research 97, 15713-15740.

Ghil, M., 1994. Cryothermodynamics: the chaotic dynamics of paleoclimate. Physica D 77, 130-159.

Hays, J., Imbrie, J., Shackleton, N., 1976. Variations in the earth's orbit: pacemaker of the ice ages. Science 194, 1121-1132.

Herbert, T., 1994. Readings orbital signals distorted by sedimentation: models and examples. In: deBoer, P., Smith, D. (Eds.), Orbital Forcing and Cyclic Sequences. Blackwell Scientific Publications, Oxford, pp. 483-507.

Heslop, D., Dekkers, M., Langereis, C., 2002. Timing and structure of the mid-pleistocene transition: records from the loess deposits of northern China. Palaeogeography, Palaeoclimatology, Palaeoecology 185, 133-143.

Huybers, P., 2004. On the origins of the ice ages: insolation forcing, age models, and nonlinear climate change. Ph.D. Thesis, MIT.

Huybers, P., 2006. Pleistocene glacial variability and the integrated insolation forcing. Science, 313, 508-511.

Huybers, P., Curry, W., 2006. Links between the annual, Milankovitch, and continuum of temperature variability. Nature 441, 329-332.

Huybers, P., Wunsch, C., 2004. A depth-derived Pleistocene age-model: uncertainty estimates, sedimentation variability, and nonlinear climate change. Paleoceanography 19.

Huybers, P., Wunsch, C., 2005. Obliquity pacing of the late-pleistocene glacial cycles. Nature 434, 491-494.

Imbrie, J., Boyle, E.A., Clemens, S.C., Duffy, A., Howard, W.R., Kukla, G., Kutzbach, J., Martinson, D.G., McIntyre, A., Mix, A.C., Molfino, B., Morley, J.J., Peterson, L.C., Pisias, N.G., Prell, W.L., Raymo, M.E., Shackleton, N.J., Toggweiler, J.R., 1992. On the structure and origin of major glaciation cycles.1. Linear responses to Milankovitch forcing. Paleoceanography 6, 205-226.

Imbrie, J., Berger, A., Boyle, E.A., Clemens, S.C., Duffy, A., Howard, W.R., Kukla, G., Kutzbach, J., Martinson, D.G., McIntyre, A., Mix, A.C., Molfino, B., Morley, J.J., Peterson, L.C., Pisias, N.G., Prell, W.L., Raymo, M.E., Shackleton, N.J., Toggweiler, J.R., 1993. On the structure and origin of major glaciation cycles. 2. The 100,000-year cycle. Paleoceanography 8, 699-735.

Le-Treut, H., Ghil, M., 1983. Orbital forcing, climatic interactions, and glaciation cycles. Journal of Geophysical Research 88, 5167-5190.

Lisiecki, L., Raymo, M., 2005. A Pliocene-Pleistocene stack of 57 globally distributed benthic $\delta^{18} \mathrm{O}$ records. Paleoceanography.

Lisiecki, L., Raymo, M. in press, Plio-Pleistocene climate evolution: trends and transitions in glacial cycle dynamics, Quaternary Science Reviews.

Liu, Z., Herbert, T., 2004. High latitude signature in Eastern Equatorial Pacific climate during the early Pleistocene epoch. Nature 427, 720-723.

Lynch-Stieglitz, J., Curry, W., Slowey, N., 1999. A geostrophic transport estimate for the Florida current from the oxygen isotope composition of benthic foraminifera. Paleoceanography 14 (3), 360-373.

Maasch, K., 1988. Statistical detection of the mid-Pleistocene transition. Climate Dynamics 2, 133-143.

Maasch, K., Saltzman, B., 1990. A low-order dynamical model of global climatic variability over the full Pleistocene. Journal of Geophysical Research 95, 1955-1963.

Marlow, J., Lange, C., Wefer, G., Rosell-Mele, A., 2000. Upwelling intensification as part of the Pliocene-Pleistocene climate transition. Science 290, 2288-2291.

Marshall, S., Clark, P., 2002. Basal temperature evolution of North American ice sheets and implications for the 100-kyr cycle. Geophysical Research Letters 29 (24).

Matteucci, G., 1990. Analysis of the probability distribution of the late pleistocene climatic record: implications for model validation. Journal of Climate 5, 35-52.

McIntyre, S., Ravelo, A., Delaney, M., 1999. North Atlantic intermediate waters in the late Pliocene to early Pleistocene. Paleoceanography 14, 324-335.

McManus, J., Oppo, D., Cullen, J., 1999. A 0.5 million year record of millennial-scale climate variability in the North Atlantic. Science 283, 971-975.

McManus, J., Oppo, D., Keigwin, L., Cullen, J., Bond, G., 2002. Thermohaline circulation and prolonged interglacial warmth in the North Atlantic. Quaternary Reviews 58, 17-21.

McManus, J., Oppo, D., Cullen, J., Healey, S., 2003. Marine Isotope Stage 11 (MIS 11): analog for Holocene and future climate? In: Droxler, A., Poore, R., Burckle, L., Osterman, L. (Eds.), Earth's Climate and Orbital Eccentricity, The Marine Isotope Stage II Question, vol. 137. American Geophysical Union, pp. 69-85.

Medina-Elizalde, M., Lea, D., 2005. The mid-Pleistocene transition in the tropical Pacific. Science 310, 1009-1012.

Meese, D., Gow, A., Alley, R., Zielinski, G., Grootes, P., Ram, M., Taylor, K., Mayewski, P., Bolzan, J., 1997. The GISP2 depth-age scale: methods and results. Journal of Geophysical Research 102C, 26411-26423.

Mix, A., Pisias, N., Rugh, W., Wilson, J., Morey, A., Hagelberg, T., 1995a. Benthic foraminifer stable isotope record from site 849 (0-5 ma): local and global climate changes. In: Pisias, N., Mayer, L., Janecek, T., Palmer-Julson, A., van Adel, T. (Eds.), Proceedings of the Ocean Drilling Program Scientific Results, vol. 138, pp. 371-412.

Mix, A., Le, J., Shackleton, N., 1995b. Benthic foraminifer stable isotope stratigraphy of site 846: 0-1.8 ma. In: Pisias, N.G., Mayer, L.A., Janecek, T., Palmer-Julson, A., van Adel, T. (Eds.), Proceedings of the Ocean Drilling Program Scientific Results, vol. 138, pp. 839-854.

Mix, A.C., 1987. Hundred-kiloyear cycle queried. Nature 327, 370.

Mudelsee, M., Schulz, M., 1997. The mid-Pleistocene climate transition: onset of $100 \mathrm{ka}$ cycle lags ice volume build-up by $280 \mathrm{ka}$. Earth and Planetary Science Letters 151, 117-123. 
Murray, R., Knowlton, C., Leinen, M., Mix, A., Polsky, C., 2000. Export production and carbonate dissolution in the Central Equatorial Pacific, Paleoceanography 15, 570-592.

Nobes, D., Bloomer, S., Mienert, J., Westall, F., 1991. Milankovitch cycles and nonlinear response in the Quaternary record in the Atlantic sector of the Southern oceans. Proceedings of the ODP, Scientific Results 114.

Oppo, D.W., McManus, J., Cullen, J., 1998. Abrupt climate events 500,000 to 340,000 years ago: Evidence from subpolar North Atlantic sediments. Science 279, 1335-1338.

Oppo, D.W., Keigwin, L., McManus, J., Cullen, J., 2001. Persistent suborbital climate variability in marine isotope stage 5 and Termination II. Paleoceanography 16, 280-292.

Paillard, D., 1998. The timing of Pleistocene glaciations from a simple multiple-state climate model. Nature 391, 378-391.

Park, J., Maasch, K.A., 1993. Plio-Pleistocene time evolution of the 100kyr cycle in marine paleoclimate records. Journal of Geophysical Research-Solid Earth 98, 447-461.

Petit, J., Jouzel, J., Raynaud, D., Barkov, N., Barnola, J., Basile, I., Bender, M., Chappellaz, J., Davis, M., Delaygue, G., Delmotte, M., Kotlyakov, M., Legrand, M., Lipenkov, V., Lorius, C., Pepin, L., Ritz, C., Saltzman, E., Stivenard, M., 1999. Climate and atmospheric history of the past 420,000 years from the Vostok ice core, Antarctica. Nature 399, 429-436.

Pisias, N., Moore, T., 1981. The evolution of Pleistocene climate: a time series approach. Earth and Planetary Science Letters 52, 450-458.

Pollard, D., 1983. A coupled climate-ice sheet model applied to the Quaternary ice ages. Journal of Geophysical Research 88, 7705-7718.

Prell, W., 1982. Oxygen and carbon isotope stratigraphy for the Quaternary of hole 502b: evidence for two modes of isotopic variability. DSDP Initial Reports 68, 455-464.

Press, W., Teukolsky, S., Vetterling, W., Flannery, B., 1999. Numerical Recipes in C. Cambridge University Press, Cambridge.

Ravelo, A., Andreasen, D., Lyle, M., Lyle, A., Wara, M., 2004. Regional climate shifts caused by gradual global cooling in the Pliocene epoch. Nature 429, 263-267.

Raymo, M., 1992. Global climate change: a three million year perspective. In: Kukla, G., Went, E. (Eds.), Start of a Glacial. NATO ASI Series I, vol. 3, pp. 207-223.

Raymo, M., 1994. The initiation of Northern Hemisphere glaciation. Annual Reviews of Earth and Planetary Science 22, 353-383.

Raymo, M., Nisancioglu, K., 2003. The 41 kyr world: Milankovitch's other unsolved mystery. Paleoceanography 18 (1).

Raymo, M., Ruddiman, W., Backman, J., Clement, B., Martinson, D., 1989. Late Pliocene variations in Northern Hemisphere ice sheets and North Atlantic deep water circulation. Paleoceanography 4, 413-446.

Raymo, M., Oppo, D., Curry, W., 1997. The mid-Pleistocene climate transition: a deep sea carbon isotopic perspective. Paleoceanography 12, 546-559.

Raymo, M., Oppo, D., Flower, B., Hodell, D., McManus, J., Venz, K., Kleiven, K., McIntyre, K., 2004. Stability of North Atlantic water masses in the face of pronounced climate variability during the Pleistocene. Paleoceanography 19.

Raymo, M.E., 1997. The timing of major climate terminations. Paleoceanography 12, 577-585.

Ruddiman, W.F., Raymo, M., Martinson, D., Clement, B., Backman, J., 1989. Pleistocene evolution: Northern Hemisphere ice sheets and the North Atlantic Ocean. Paleoceanography 4, 353-412.

Saltzman, B., Sutera, A., 1987. The mid-Quaternary climatic transition as the free response of a three-variable dynamical model. Journal of the Atmospheric Sciences 44, 236-241.

Saltzman, B., Hansen, A., Maasch, K., 1984. The late Quaternary glaciations as the response of a three-component feedback system to
Earth-orbital forcing. Journal of the Atmospheric Sciences 41 (23), 3380-3389.

Schreiber, T., Schmitz, A., 2000. Surrogate time series. Physica D 142, 346-382.

Shackleton, N., 1995. New data on the evolution of Pliocene climatic variability. In: Vrba, E., Denton, G., Partridge, T., Burckle, L. (Eds.), Paleoclimate and Evolution with Emphasis on Human Origins. Yale University Press, New Haven, CT, pp. 242-248.

Shackleton, N.J., Hall, M., 1984. Oxygen and carbon isotope stratigraphy of Deep-Sea Drilling Project hole 552a: Plio-Pleistocene glacial history. DSDP Initial Reports 81, 599-609.

Shackleton, N.J., Imbrie, J., Pisias, N.G., 1988. The evolution of oceanic oxygen-isotope variability in the North-Atlantic over the past 3 million years. Philosophical Transactions of the Royal Society of London Series B-Biological Sciences 318, 679-688.

Shackleton, N.J., Berger, A., Peltier, W.R., 1990. An alternative astronomical calibration of the lower Pleistocene timescale based on ODP site 677. Transactions of the Royal Society of Edinburgh-Earth Sciences 81, 251-261.

Shaw, A., 1964. Time in Stratigraphy. McGraw-Hill, New York.

Singer, B., Pringle, M., 1996. Age and duration of the Matuyama-Brunhes geomagnetic polarity reversal from ${ }^{40} \mathrm{Ar} /{ }^{39} \mathrm{Ar}$ incremental analysis of lavas. Earth and Planetary Science Letters 139, 47-61.

Strogatz, S., 1994. Nonlinear Dynamics and Chaos. Perseus Publishing.

Tauxe, L., Herbert, T., Shackleton, N., 1996. Astronomical calibration of the Matuyama Brunhes boundary: consequences for magnetic remanence acquisition in marine carbonates and the Asian loess sequences. Earth and Planetary Science Letters 140, 133-146.

Thompson, W.G., Goldstein, S.L., 2005. Open-system coral ages reveal persistent suborbital sea-level cycles. Science 308, 401-404.

Thomson, P.J., Robinson, P.M., 1996. Estimation of second-order properties from jittered time series. Annals of the Institute of Statistical Mathematics 48, 29-48.

Tiedemann, R., Sarnthein, M., Shackleton, N.J., 1994. Astronomic timescale for the Pliocene Atlantic $\delta^{18} \mathrm{O}$ and dust flux records of ODP site 659. Paleoceanography 9, 619-638.

Tziperman, E., Gildor, H., 2003. On the mid-Pleistocene transition to 100kyr glacial cycles and the asymmetry between glaciation and deglaciation times. Paleoceanography 18.

Tziperman, E., Raymo, M., Huybers, P., Wunsch, C. Consequences of pacing the Pleistocene $100 \mathrm{kyr}$ ice ages by nonlinear phase locking to Milankovitch forcing. Paleoceanography, in press.

Upton, G., Fingleton, B., 1989. Spatial Data Analysis by Example. vol. 2. Wiley, Chichester, UK.

Venz, K., Hodell, D., Stanton, C., Warnke, D., 1999. A 1.0 Myr record of glacial North Atlantic intermediate water variability from ODP site 982 in the Northeast Atlantic. Paleoceanography 14, 42-52.

Wara, M., Ravelo, C., Delaney, M., 2005. Permanent El Niñolike conditions during the Pliocene warm period. Science 309, 758-761.

Williams, D., Thunell, R., Tappa, E., Rio, D., Raffi, I., 1988. Chronology of the Pleistocene oxygen isotope record: $0-1.88$ m.y. b.p. Palaeogeography, Palaeoclimatology, Palaeoecology 64, 221-240.

Wunsch, C., 2004. Quantitative estimate of the Milankovitch-forced contribution to observed quaternary climate change. Quaternary Science Reviews 23, 1001-1012.

Yiou, P., Genthom, C., Ghil, M., Jouzel, J., Barnola, J., Lorius, C., Korotkevitch, Y., 1991. High-frequency paleovariability in climate and $\mathrm{CO}_{2}$ levels from Vostok ice core records. Journal of Geophysical Research 96, 20365-20378.

Zachos, J., Pagani, M., Sloan, L., Thomas, E., Billups, K., 2001. Trends, rhythms, and aberrrations in global climate $65 \mathrm{Ma}$ to present. Science 292, 686-693. 